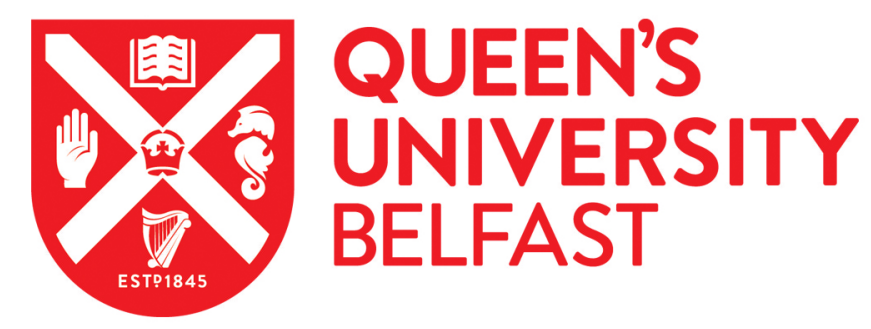

\title{
Rehydroxylation (RHX) dating: Mass loss issues due to incomplete drying, carbon content, and mineral alteration
}

Barrett, G. (2017). Rehydroxylation (RHX) dating: Mass loss issues due to incomplete drying, carbon content, and mineral alteration. Journal of Archaeological Science Reports. https://doi.org/10.1016/j.jasrep.2017.02.001

Published in:

Journal of Archaeological Science Reports

Document Version:

Peer reviewed version

Queen's University Belfast - Research Portal:

Link to publication record in Queen's University Belfast Research Portal

Publisher rights

(c) 2017 Elsevier Ltd. All rights reserved.

This manuscript version is made available under the CC-BY-NC-ND 4.0 license http://creativecommons.org/licenses/by-nc-nd/4.0/

\section{General rights}

Copyright for the publications made accessible via the Queen's University Belfast Research Portal is retained by the author(s) and / or other copyright owners and it is a condition of accessing these publications that users recognise and abide by the legal requirements associated with these rights.

Take down policy

The Research Portal is Queen's institutional repository that provides access to Queen's research output. Every effort has been made to ensure that content in the Research Portal does not infringe any person's rights, or applicable UK laws. If you discover content in the Research Portal that you believe breaches copyright or violates any law, please contact openaccess@qub.ac.uk. 
Title:

2 Rehydroxylation (RHX) Dating: Mass Loss Issues due to Incomplete Drying, Carbon Content, and Mineral

3 Alteration.

4 Author Name and Affiliation:

5 Gerard Thomas Barrett, Ph.D.

$6{ }^{14}$ CHRONO Center for Climate, the Environment, and Chronology, School of Natural and Built Environment,

7 Queen's University Belfast, Elmwood Avenue, Belfast BT7 1NN, Northern Ireland, UK

8 Email: g.barrett@qub.ac.uk

Abstract:

11 As part of rehydroxylation (RHX) dating trials on post-medieval bricks, investigations were carried out into the

12 presence, and effect on age estimations, of uncertainties associated with (a) prolonged and incomplete drying of

13 samples, (b) the removal of organic and non-organic matter during heating, and (c) mineral alteration during heating.

14 All samples exhibit an issue with a prolonged period of drying, exceeding two months at $130^{\circ} \mathrm{C}$. Methods for treating

15 this issue are applied and demonstrate the need for higher resolution and more precise monitoring of the mass loss

16 during drying if the moisture not removed needs to be taken account of; this may not be necessary if prolonged drying

17 is associated with the slow removal of chemisorbed water, distinct from rehydroxylation-related water loss. Organic

18 matter contamination is also present in significant quantities in all samples, regardless of the retrieval context; the

19 considerable effects of uncertainties in this quantity, arising from variability in the organic matter to organic carbon

20 ratio $(\mathrm{OM} / \mathrm{OC})$, on age estimations are presented. Mineral alteration during reheating is generally negligible except

21 when gypsum is present; large sources of uncertainty arising from moisture loss associated with dehydration and with

22 subsequently lower levels of physisorption following reheating are highlighted as problematic.

\section{Keywords:}

24 Rehydroxylation, Dating, Drying, Contaminants, Minerals, Components 


\section{Introduction}

The potential of rehydroxylation dating as an archaeological tool showed early promised (Wilson 2009; 2012) but has since suffered from an absence of successful applications (e.g. Burakov et al. 2013; Le Goff and Gallet 2015a; Numrich et al. 2015) and the identification of a range of issues surrounding the method (e.g. Bowen et al. 2011; 2013; Le Goff and Gallet 2015a; 2015b; Gallet and Le Goff 2015; see also the review in Barrett 2015). These often focus on the mass gain behavior that is central to the method, for example the suitability of a $t^{1 / 4}$ model (e.g. Bowen et al. 2011; Le Goff and Gallet 2014; 2015b; Gallet and Le Goff 2015; Barrett 2017b) or the equilibration of the mass following drying (e.g. Le Goff and Gallet 2014; Gallet and Le Goff 2015). However, there are also issues surrounding estimation of the amount of mass, due to rehydroxylation (uptake of atmospheric moisture that is subsequently chemically bound to the ceramic matrix), gained by the ceramic since it was last dehydroxylated (i.e. originally fired or last heated above $500^{\circ} \mathrm{C}$ ). This mass is critical to age calculations and can be retrieved based on the mass loss that occurs during reheating at $500^{\circ} \mathrm{C}$ (Wilson 2012). There may be components of this mass loss that have other origins and need to be taken account of: incomplete drying (Bowen et al. 2011; Barrett 2015) may result in a quantity of loose or capillary water later removed at the higher reheating temperature; organic carbon may be burnt off between 200$500^{\circ} \mathrm{C}$ (Numrich et al. 2014); and minerals may undergo alteration and contribute additional mass loss, i.e. goethite (Burakov and Nachasova 2013). These mass loss issues, particularly incomplete drying and organic matter, have not received enough focused attention. As part of a larger work aimed at assessment of the archaeological application of RHX dating (Barrett 2015; 2017a; 2017b), these factors were explored, pre-planned in the case of organic contaminants and mineral alteration but necessitated unexpectedly in the case of indefinite drying; the dating trial results are presented in the companion article (Barrett 2017a).

The results of mass loss data for drying granulated samples will be presented together with modelling attempts to account for any remaining moisture (mass) in the fabric. The potential effect this estimated remaining mass has on age estimations from dating trials (Barrett 2015; 2017a) will be explored. As well as this, an explanation for prolonged drying will be suggested.

The presence and nature of organic matter, lost during heating, are examined using Fourier transform infrared spectroscopy (FTIR), carbon content analysis, and thermogravimetric mass spectrometry (TG-MS). The mass loss 
51 uncertainties (and their age estimation impact) that arise from issues with the organic matter to organic carbon

$52(\mathrm{OM} / \mathrm{OC})$ ratio will be explored.

53 Finally, the effects of reheating on the mineral composition are examined through x-ray diffractometry (XRD) and

54 FTIR.

55 Note that in the associated dating trials both mass gain models, $t^{1 / 4}$ and $t^{1 / n}$, were applied for reasons discussed in

56 Barrett (2017a). While the latter was preferred, the age estimations produced using both approaches were problematic.

57 The present work discusses mass loss effects in relation to both, with preference often given to the use of the $t^{1 / 4}$ model

58 results in illustrating the magnitude of potential effects (of relevance in re-examining successful RHX dating trials

59 that used this model, i.e. Wilson et al. 2009; 2012); counterpart effects for the $t^{l / n}$ model can be found in Barrett (2015)

60 and are not included here if the magnitude of the effect is very similar to that for the $t^{1 / 4}$ model such that it does not

61 alter or contribute significantly to the main conclusions and arguments being made.

\section{2. Method}

\section{$63 \quad 2.1 \quad$ Samples}

64 The sample set (see supplementary materials Table $S 1$ and $S 2$ ) is described in more detail (including compositional, 65 surface area, firing information, origin, context) in the companion article (Barrett 2017a) and more comprehensively 66 elsewhere (Barrett 2015). It was composed of 18 samples, including 14 brick samples from the island of Ireland, 2 67 pottery samples from Northern Ireland, and a piece of Roman and Etruscan ceramics; the brick and pottery samples were of post-medieval age (Table S1). Samples were retrieved from both buried (9) and non-buried (9) contexts (Table

69 S2). Brick samples (of particular importance as they provided all 12 samples suitable for age estimates in Barrett $702015 ; 2017$ a) were likely produced from residual/boulder clays (rich in quartz and feldspars and generally low in 71 calcium content) that were well fired above $850^{\circ} \mathrm{C}$ (Barrett $\left.2015 ; 2017 \mathrm{a}\right)$. The specific surface area of samples was 72 quite variable but typically $<5 \mathrm{~m}^{2} / \mathrm{g}$ (Table S.3).

\section{$73 \quad 2.2 \quad$ Drying and Loose Water Modelling}

74 Drying at $130^{\circ} \mathrm{C}$ was conducted during dating trials (Barrett 2015; 2017a) to remove any non-rehydroxyl moisture 75 from the ceramic (i.e. pore or capillary bulk moisture). Samples had already undergone extensive pre-drying at 76 approximately $80^{\circ} \mathrm{C}$ for 15 days during preparation before this stage (see Barrett 2015). For drying, granulated 
77 samples (typically $>80 \mathrm{~g}$ of $2-5.6 \mathrm{~mm}$ sieved fractions, each granule approx.. 0.05-0.15g) were spread out on 78 aluminium trays and placed in an oven (fan assisted) at $130^{\circ} \mathrm{C}$ (granulation was conducted to homogenize sample 79 material, originally quite heterogeneous, before it was split into three subsamples for dating trials). Based on the 80 existing literature (see Discussion), it was assumed that samples would dry to constant mass within a reasonable period 81 of time (maximum of a couple of weeks). On a near daily basis, the trays were removed and weighed on a top-loading 82 balance under room conditions of $20 \pm 1^{\circ} \mathrm{C}$ and $78 \pm 3 \% \mathrm{RH}$. Samples were weighed under a rigid timing regime for 83 two months; it was recognized from the mass loss curves that after a month of repeated measurements equilibration 84 to constant mass appeared unlikely with measurements continued for an additional month to improve the quality of 85 the mass loss curves.

86 Modelling of the drying curves was carried out to provide an estimate of the magnitude of loosely bound water, $m_{l w}$, 87 not removed during drying (presumed to be removed when samples are reheated at $500^{\circ} \mathrm{C}$ as part of dating trials).

88 Two empirical models of drying were applied using the curve fitting tool cftool in MATLAB R2012a: where $X$ is the moisture content, $X_{e}$ is the equilibrium moisture content (i.e. 0 for an idealised dry ceramic) and $b$ is the drying constant. Lewis (1921) considered that during drying of porous and hygroscopic materials, the rate of loss

Model 1 (Power): $\quad m(t)=a\left(t^{-b}\right)+c$

where $a$ is the mass rate, $b$ is the power of the model, and $c$ is the final dry mass of the ceramic.

Model 2 (Exponential): $\quad m(t)=a e^{-b t}+c$

where $a$ and $b$ (drying constant) are coefficients that determine the rate of moisture loss and $c$ the final dry mass of the ceramic.

The former of these models was trialled based on the emphasis of the prevalence of $t^{1 / 2}$ transport processes in ceramic materials (Brosnan and Robinson 2003). However, it was found that the $1 / 2$ power was a poor descriptor of the behaviour observed; hence the power constraint was relaxed.

The latter of these two models is derived from Lewis' (1921) thin-layer equation:

$$
\frac{d X}{d t}=b\left(X-X_{e}\right)
$$
of moisture is proportional to the difference between the moisture content and the moisture content when the material 
102 is at equilibrium (dry) with the drying environment. This thin-layer equation assumes that the conditions of drying 103 (humidity, temperature) are constant throughout the material during drying. Forms of this equation are commonly 104 used in fundamental modelling of drying (see Pakoswki and Mujumbar 2006 and Marinos-Kouris and Maroulis 105 2006)).

106 The power model proved unsatisfactory (see Results and Discussion) and the exponential model was instead selected 107 for complete modelling and calculation of the $m_{l w}$ values. This model was used to estimate the completely dry mass 108 of the sample trays and the mass at 61, 62, 63 and 66 days (when groups of samples were removed for commencement 109 of mass gain measurements), with the difference between these two amounting to the potential remaining moisture 110 that could be removed upon heating at $500^{\circ} \mathrm{C}$. Uncertainties at the $95 \%$ confidence level were calculated from the 111 upper and lower bounds on the model coefficients estimated in MATLAB.

\section{$112 \quad 2.3 \quad$ Thermogravimetric Mass Spectrometry}

113 TG-MS was carried out using a Netzsch TG 209 F1 Libra thermo-microbalance in series with a Pfeiffer Thermostar 114 mass spectrometer. Approximately $30-40 \mathrm{mg}$ of powdered dating sample $(<63 \mu \mathrm{m})$ was used. The samples had 115 previously been dried at $130^{\circ} \mathrm{C}$ and stored in a desiccated environment for a period of three months. The sample was 116 placed in an $\mathrm{Al}_{2} \mathrm{O}_{3}$ crucible within the $T G 209$ and heated from $25^{\circ} \mathrm{C}$ to $1000^{\circ} \mathrm{C}$ at a rate of $20^{\circ} \mathrm{C} / \mathrm{min}$ under a constant 117 flow of nitrogen at $50 \mathrm{~mL} / \mathrm{min}$. Mass spectrometry was carried out for ions of mass number $18\left(\mathrm{H}_{2} \mathrm{O}\right), 44\left(\mathrm{CO}_{2}\right)$ and $11864\left(\mathrm{SO}_{2}\right)$, liberated during the heating process. Sampling of the mass and ion current (mass spectrometry) was carried 119 out for each ${ }^{\circ} \mathrm{C}$ increment in temperature.

120 Analysis (identification of events and structures) of the mass loss curve, its first derivative, and ion fragment curves 121 was carried out after smoothing (typically a moving average with $n=11$ ).

\section{$122 \quad 2.4 \quad$ Carbon Content and Organic Matter Mass}

123 Carbon content analysis was carried out at the ${ }^{14}$ CHRONO Centre at Queen's University Belfast. For each dating 124 sample, carbon content analysis was carried out on two subsamples of approximately $0.5 \mathrm{~g}$ powdered form $(<63 \mu \mathrm{m})$; 125 one sample that had been dried at $130^{\circ} \mathrm{C}$ and another that had been fired at $500^{\circ} \mathrm{C}$ (these subsamples came from 126 powdering of remaining (typically $10-20 \mathrm{~g}$ ) homogenised sample material not used in dating). Samples were

127 combusted (in the presence of copper oxide and strips of silver) in quartz-glass tubes at $850^{\circ} \mathrm{C}$ for 8 hours. Then the 
sample was opened into a cryogenic separation line and the $\mathrm{CO}_{2}$ gas pressure in a specific volume recorded and converted to a mass of carbon using a laboratory conversion factor. The ratio of the mass of carbon to the original mass of the sample was used to calculate the \%wt C (carbon).

131 For each dating sample, this provided two values, the $\%$ wt $\mathrm{C}$ for the sample dried at $130^{\circ} \mathrm{C}$ (corresponding to mass $132 m_{c 130+}$ ) and the \%wt $\mathrm{C}$ for the sample heated at $500^{\circ} \mathrm{C}$ (corresponding to mass $m_{c 500^{+}}$). To obtain the \%wt $\mathrm{C}$ removed from a sample during heating between $130-500^{\circ} \mathrm{C}\left(m_{c}\right)$ the following equation was used:

$$
m_{c}=m_{c 130+}-m_{c 500+}
$$

As part of dating trials (Barrett 2015, 2015b), before the age of the ceramic could be calculated an estimate of the organic matter mass, $m_{o m}$, removed during reheating must be subtracted from the total mass loss during reheating. In order to do this the carbon content must be multiplied by an organic matter to organic carbon ratio, OM/OC:

$$
m_{O M}=O M / O C \times m_{c}
$$

139 For age calculations, a standard value of 1.95 was used for $O M / O C$ across all samples. For assessment of the effect 140 of variation in the $O M / O C$, a range of 1.4-2.5 was used (Pribyl 2010; see Barrett 2015 Section 2.5 for a summary 141 review of the literature upon which these values were selected).

\section{$142 \quad 2.4 \quad$ FTIR and XRD}

143 FTIR analysis (Russell and Fraser 1994) was carried out using a PerkinElmer Spectrum One. For each dating sample, 144 two powdered subsamples $(<63 \mu \mathrm{m})$ were prepared into pressed pellets, a sample that had previously been dried at $145130^{\circ} \mathrm{C}$ (3 months) and a sample that had been fired at $500^{\circ} \mathrm{C}$ (for 18 hours). This was achieved by mixing 146 approximately $2-5 \mathrm{mg}$ of sample with $40-100 \mathrm{mg}$ of potassium bromide $(\mathrm{KBr})$ and compressing the pellet in an 147 evacuated die under high pressure (10 tons) to form a pressed disc of diameter $13 \mathrm{~mm}$ and thickness $<1 \mathrm{~mm}$. These 148 discs were then dried in an oven at $130^{\circ} \mathrm{C}$ for a minimum of 3 hours to remove any loosely bound surface adsorbed 149 water before being placed in a desiccated jar to cool. Scans were then run on room temperature samples over the 150 wavenumber range $450 \mathrm{~cm}^{-1}-4000 \mathrm{~cm}^{-1}$. The Spectrum One software was used to carry out a baseline correction on each of the scans. 
152 Using MATLAB, the second derivative of the FTIR spectrum and a smoothed version of this second derivative (using 153 cftool and a smoothing spline with smoothing parameter 0.0133 ) were acquired. The main absorption peaks were 154 identified through comparison of the FTIR scan and its $2^{\text {nd }}$ derivative with the mineral identification (carried out 155 largely over the region $1500-450 \mathrm{~cm}^{-1}$ ) using tables compiled from the following references: Benedetto et al. 2002; 156 Chukanov 2014; Russell and Fraser 1994; van der Marel and Beuterspacher 1976.

157 Special attention was also paid to the region $3000-2800 \mathrm{~cm}^{-1}$ where absorption peaks associated with organics were 158 compiled and tabulated.

159 XRD analysis was also carried out on powdered $(<63 \mu \mathrm{m})$ subsamples of both dried $\left(130^{\circ} \mathrm{C}\right.$ for 3 months $)$ and reheated $160\left(500^{\circ} \mathrm{C}\right.$ for $\left.18 \mathrm{hrs}\right)$ dating samples. Approximately $1-2 \mathrm{~g}$ of powder, enough to fill a $16 \mathrm{~mm}$ diameter holder of depth $1612.4 \mathrm{~mm}$, was required per subsample. X-ray diffractometry was then carried out with a PANalytical X'Pert Pro system 162 using $\mathrm{Cu}-\mathrm{K} \alpha$ radiation. Scans were run over the range $3-63^{\circ}(2 \theta)$ with a step size of $0.0170(2 \theta)$ and scan step time 163 of 120 s (total scan time of 58 minutes per sample).

164 Analysis of the XRD spectra (Moore and Reynolds 1997) was carried out using the powder pattern analysis tool 165 PANalytical X'Pert Highscore Plus (Highscore 2015). The spectra had the following treatments carried out in the 166 following order: background removal; smoothing (quantic polynomial over a window size of $n=15$ ); peak search 167 (using the minimum of the $2^{\text {nd }}$ derivative method and a minimum peak significance of 15 counts); convert FDS to 168 ADS correction; search and match algorithm to identify the possible minerals present using the International Center 169 for Diffraction Data (ICDD) library PDF2. Identification of minerals present was based on both peak and profile 170 matching with the library spectra available.

$172 \quad$ 3. Results

\section{$173 \quad 3.1 \quad$ Drying, Loose Water and Effects}

174 The goodness-of-fit results $\left(R^{2}\right.$ and $\left.R M S E\right)$ of the application of both drying models to the drying mass curves are 175 presented in Table 1 with examples of the modelled fits displayed in Figure 1 for both well behaved (Joy, top) and 176 abnormally (Lan, bottom) behaved samples. The terminology 'well behaved' and 'abnormal' samples corresponds to 177 samples that displayed mass gain curves that were well suited (a clear Stage 2 behaviour that is linear as a function of 
$t^{l / n}$ together with an Arrhenius temperature dependence for the mass gain rate) or poorly suited for age estimate modelling; this is discussed in the companion article (Barrett 2017a). Differences in the goodness-of-fits between the two drying models are minor and alone are not significant enough to merit giving preference to either model.

181 To further examine the strength of both models, the modelled loose water content, as a fraction of the modelled dry 182 mass, was correlated against properties of the ceramic that would be expected to have a strong/moderate relationship with moisture content (\%wt. loss between $50-130^{\circ} \mathrm{C}$ from TG-MS results, BET surface area and pore volume (Barrett 2015; 2017a; 2017b, see also Table S3)), Table 2, and provide stronger support for the use of Model 2.

Table 1: Comparison of goodness-of-fit estimates for two models applied to drying curves of dating samples.

\begin{tabular}{|l|c|c|c|c|}
\hline & $\begin{array}{l}\text { Model 1 } \\
\left(\boldsymbol{m}(\boldsymbol{t})=\boldsymbol{a}\left(\mathbf{t}^{\boldsymbol{b}}\right)+\boldsymbol{c}\right)\end{array}$ & $\begin{array}{l}\text { Model 2 } \\
\left(\boldsymbol{m}(\mathbf{t})=\boldsymbol{a}\left(\mathbf{e x p}^{-\boldsymbol{b t}}\right)+\boldsymbol{c}\right)\end{array}$ & \\
\hline & $\boldsymbol{R}^{\mathbf{2}}$ & RMSE $(\mathbf{g})$ & $\boldsymbol{R}^{\mathbf{2}}$ & RMSE $(\boldsymbol{g})$ \\
\hline Ann & 0.67 & 0.008 & 0.66 & 0.008 \\
\hline Esp & 0.16 & 0.006 & 0.17 & 0.006 \\
\hline Nic & 0.72 & 0.008 & 0.71 & 0.008 \\
\hline Mac & 0.90 & 0.009 & 0.93 & 0.009 \\
\hline Ria & 0.96 & 0.008 & 0.95 & 0.008 \\
\hline Etr & 0.81 & 0.025 & 0.90 & 0.025 \\
\hline Rom & 0.82 & 0.016 & 0.82 & 0.016 \\
\hline Por & 0.90 & 0.017 & 0.94 & 0.017 \\
\hline Rat & 0.89 & 0.006 & 0.89 & 0.006 \\
\hline Cal & 0.95 & 0.007 & 0.94 & 0.007 \\
\hline Lan & 0.72 & 0.016 & 0.79 & 0.016 \\
\hline Joy & 0.96 & 0.008 & 0.95 & 0.008 \\
\hline Cau & 0.78 & 0.008 & 0.83 & 0.008 \\
\hline Bel & 0.90 & 0.013 & 0.93 & 0.013 \\
\hline Dow1 & 0.81 & 0.017 & 0.89 & 0.017 \\
\hline Dow2 & 0.91 & 0.009 & 0.93 & 0.009 \\
\hline Tur & 0.92 & 0.009 & 0.91 & 0.009 \\
\hline Ted & 0.86 & 0.008 & 0.91 & 0.008 \\
\hline
\end{tabular}




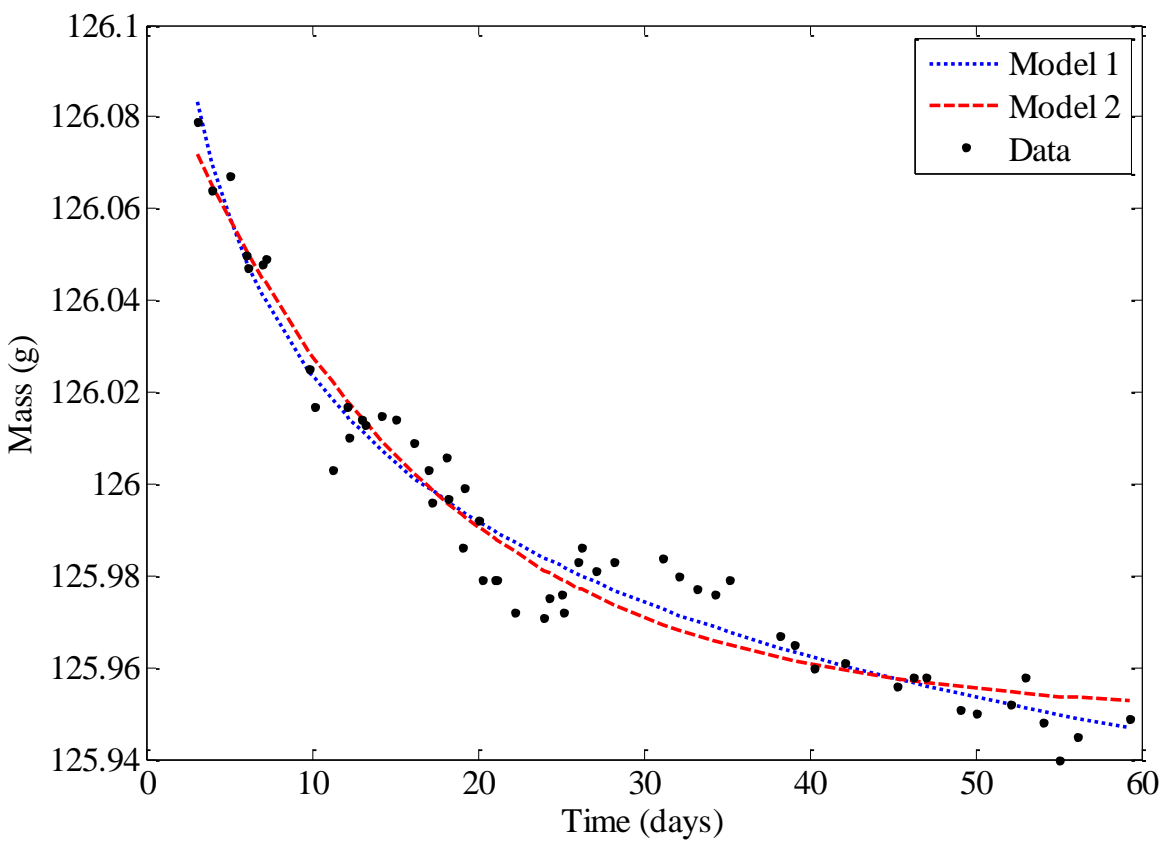

198

Time (days)

199

200

201

202

203

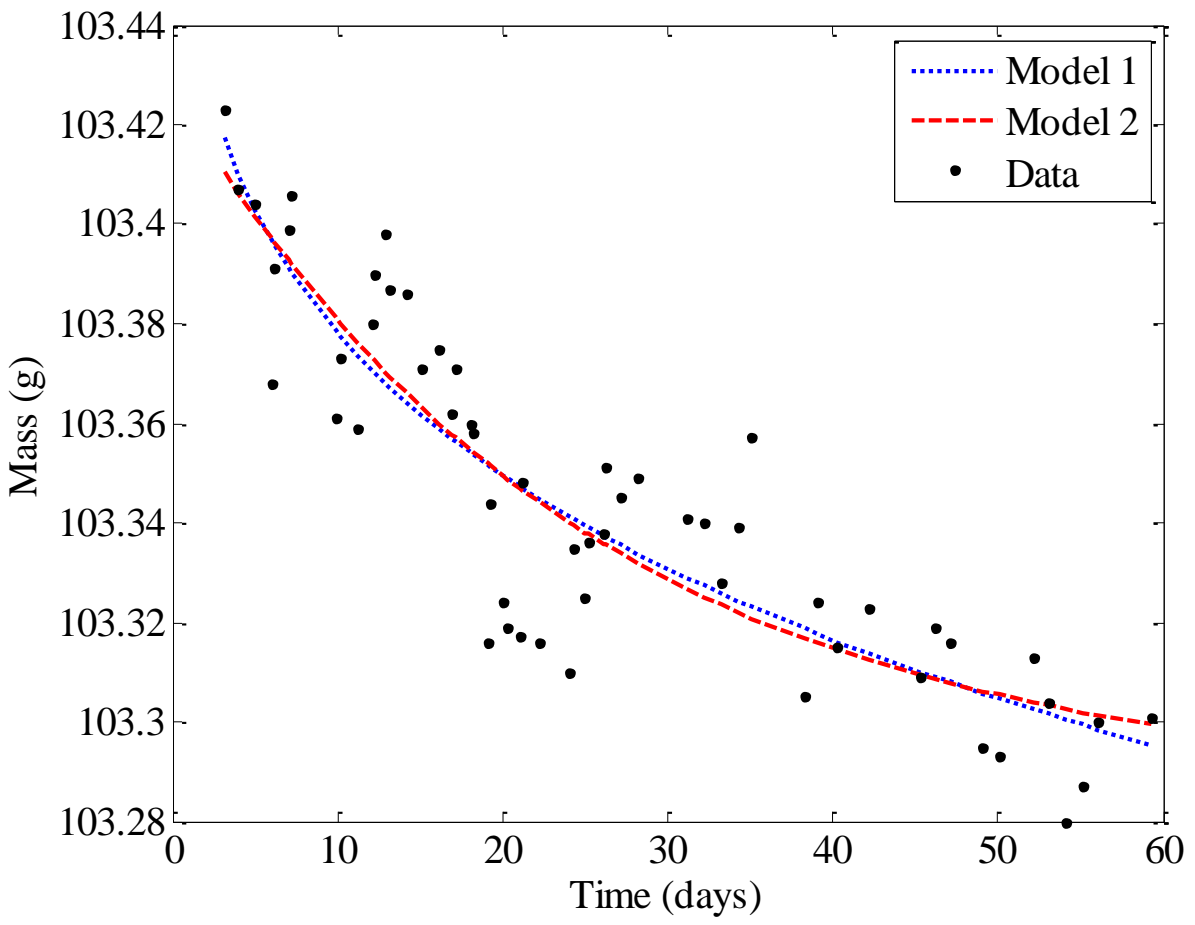

207

Figure 1: Drying mass curves for Joy (top) and Lan (bottom) with two models applied. Red dashed $=$ exponential model; blue dotted $=$ power model . 
Table 2: Assessment, for both drying models, of the level of correlation $\left(R^{2}\right)$ between the remaining water content (as a fraction of the estimated dry mass) and various proxies for the potential moisture content of the sample (BET S. A. and pore volume from Barrett 2015). From linear regressions carried out across all dating samples.

\begin{tabular}{|l|l|l|l|}
\hline versus & TG-MS $50-130^{\circ} \mathrm{C} \% w t$ loss & BET Surface Area & Pore Volume \\
\hline Model 1 ( $\boldsymbol{R}^{2}$ value) & 0.11 & 0.04 & 0.10 \\
\hline Model 2 ( $\boldsymbol{R}^{\mathbf{2} \text { value) }}$ & 0.53 & 0.38 & 0.43 \\
\hline
\end{tabular}

The modelled loose water content remaining in the dried samples, after 60 days drying and given as a percentage of the modelled dry mass, is presented in Figure 2 and arranged in order of dryness with 95\% confidence intervals included also. It is notable that many of the samples with the largest values of loose water are samples (Etr, Lan, Dowl/2,Por, Mac,Bel) considered problematic in related work due to having a high specific surface area (Table S.3) that results in potential capillary condensation issues (Barrett 2015; 2017b). The sample $E s p$ is significant as it appears to be the only sample to have dried out.

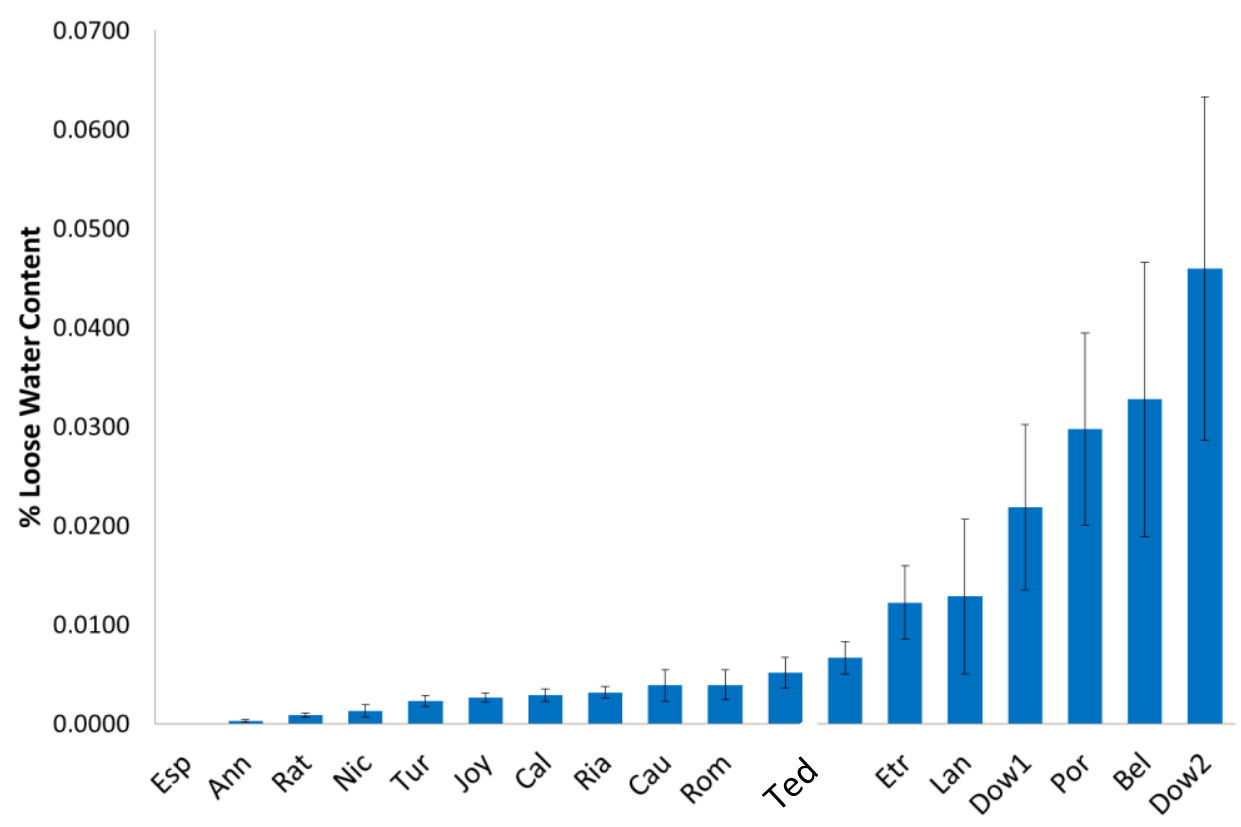

Figure 2: The modelled loose water content, as a percentage of the modelled dry mass of samples (Model 2), remaining after 60 days drying at $130^{\circ} \mathrm{C}$. Arranged in order of dryness and with $95 \%$ confidence intervals.

For examination of the implications with regard to RHX dating, the mass of loose water, $m_{l w}$, is presented as a percentage of the total mass loss, $m_{R H X C}$, during reheating at $500^{\circ} \mathrm{C}$ (with regard to application of a $t^{1 / 4}$ model; similar 


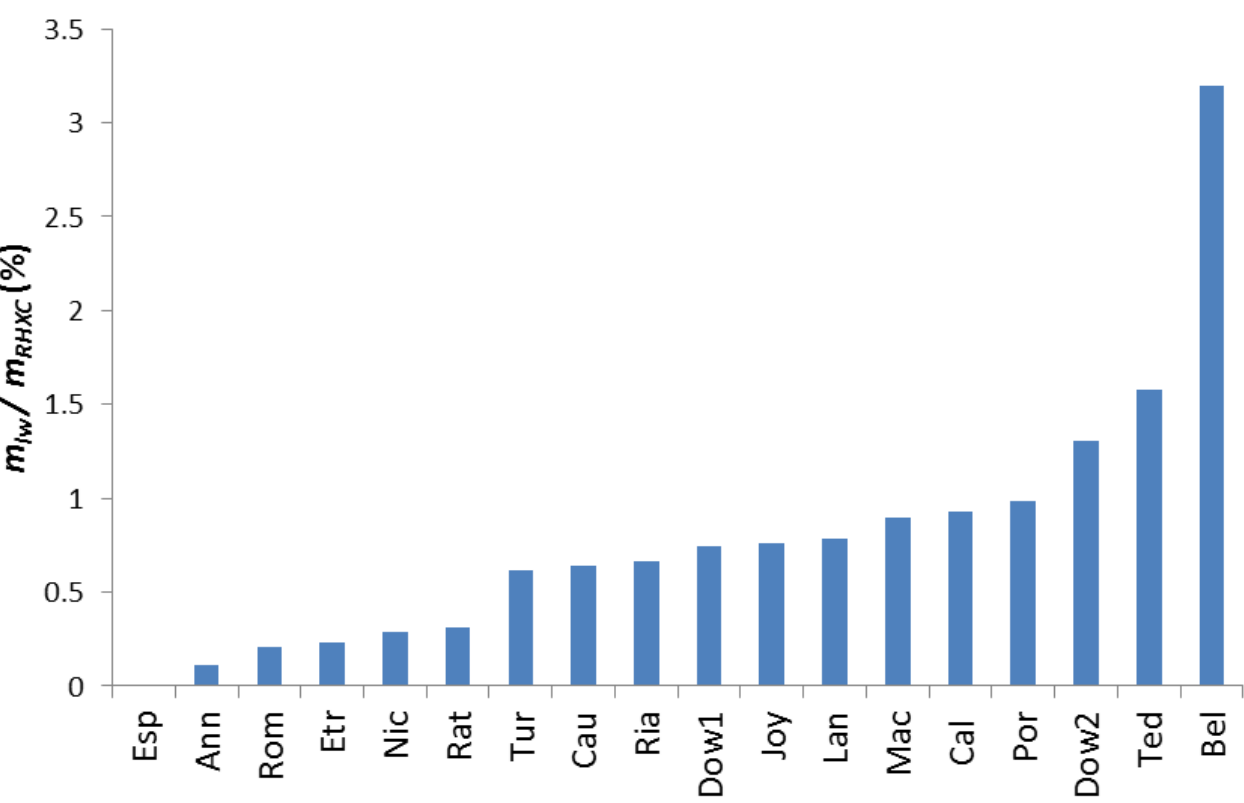
heating between $130^{\circ} \mathrm{C}$ and $500^{\circ} \mathrm{C}$. For $t^{1 / 4}$ model.

\subsection{TG-MS}

The full set of TG-MS curves are provided in Barrett (2015). A summary of the TG-MS features observed are

247 presented in Table 3. To illustrate the main heating events in this table associated with $\mathrm{CO}_{2}$ (organic/inorganic carbon)

248 loss, Figure 4 presents the mass spectrometry curve for mass $44\left(\mathrm{CO}_{2}\right)$ with events E-G labelled. The $\mathrm{CO}_{2}$ associated 249 events occur over the temperature regime $200-800^{\circ} \mathrm{C}$ and are classified as follows:

E: $\quad 200-300^{\circ} \mathrm{C}-$ onset of organic $\mathrm{CO}_{2}$ mass loss.

F: $\quad 400-500^{\circ} \mathrm{C}-$ organic $\mathrm{CO}_{2}$ peak ('increasing' implies peak not clear due to overlap with inorganic peak.

G: $\quad 600-750^{\circ} \mathrm{C}-$ inorganic $\mathrm{CO}_{2}$ peak (carbonates). 
clear peak and overlap with inorganic calcite-related peak) together with position of inorganic carbon (calciterelated) peak (event $G$ ). The presence/absence of $\mathrm{SO}_{2}$ removal is also provided.

\begin{tabular}{|c|c|c|c|c|c|c|c|c|}
\hline \multirow[b]{2}{*}{ Event } & \multicolumn{4}{|c|}{$\begin{array}{l}\mathrm{H}_{2} \mathrm{O} \text { peaks (yellow = weak, orange = } \\
\text { medium, red =strong) }\end{array}$} & \multirow{2}{*}{$\begin{array}{r}\mathrm{CO}_{2} \\
\text { onset } \\
E\end{array}$} & \multirow{2}{*}{$\begin{array}{c}\text { Organic } \\
\mathrm{CO}_{2} \max . \\
F\end{array}$} & \multirow{2}{*}{$\begin{array}{c}\text { Inorganic } \\
\mathrm{CO}_{2} \text { max. } \\
G\end{array}$} & \multirow{2}{*}{$\begin{array}{l}\text { SO2 } \\
\text { (a=absent; } \\
p=p r e s e n t\end{array}$} \\
\hline & $A$ & $B$ & $C$ & $D$ & & & & \\
\hline Ann & 70 & 130 & - & 310 & $250-300$ & $450-500$ & 620 & $a$ \\
\hline Esp & $60-70$ & 110 & $260-270$ & - & $250-300$ & increasing & $610-620$ & $\mathrm{a}$ \\
\hline Nic & 50 & - & $210-230$ & - & $250-300$ & 400 & 690 & $\mathrm{a}$ \\
\hline Mac & 90 & - & - & $310-320$ & $200-250$ & $410-420$ & trace & $p$ \\
\hline Ria & 50 & $120-160$ & - & $320-330$ & $250-300$ & $450-500$ & $610-620$ & a \\
\hline Etr & 90 & - & 240 & - & $200-250$ & increasing & $730-740$ & $a$ \\
\hline Rom & $90-100$ & - & $230-240$ & - & $250-300$ & $450-500$ & $740-750$ & $a$ \\
\hline Por & $60-70$ & - & - & $310-340$ & $250-300$ & increasing & $710-720$ & $a$ \\
\hline Rat & 60 & $160-170$ & - & 350 & $250-300$ & $450-500$ & $600-610$ & a \\
\hline Cal & 60 & 140 & - & $340-350$ & $300-350$ & $430-450$ & $630-640$ & $a$ \\
\hline Lan & 90 & - & 210 & $350-400$ & $300-350$ & increasing & $640-650$ & $a$ \\
\hline Joy & 60 & 150 & - & $310-320$ & $250-300$ & - & 630 & $a$ \\
\hline Cau & 70 & $130-140$ & $270-280$ & - & $250-300$ & $450-500$ & $640-650$ & a \\
\hline Bel & $90-100$ & - & $250-300$ & - & $230-250$ & 480 & 680 & $p$ \\
\hline Dow1 & $80-90$ & - & $200-250$ & $340-390$ & $250-300$ & 370 & $730-740$ & $a$ \\
\hline Dow2 & $95-110$ & - & - & $350-400$ & $250-300$ & $480-530$ & 750 & a \\
\hline Tur & $60-70$ & $140-160$ & - & $310-330$ & $250-300$ & $450-500$ & $570-580$ & a \\
\hline Ted & - & $170-180$ & - & $290-310$ & $270-300$ & 450 & $650-670$ & a \\
\hline
\end{tabular}
was observed for $\mathrm{Mac}$ and $\mathrm{Bel}$ with $\mathrm{SO}_{2}$ removal occurring above $650-700^{\circ} \mathrm{C}$. $\mathrm{CO}_{2}$ loss occur in the region $250-350^{\circ} \mathrm{C}$, typically, with a plateau of emission common from $450^{\circ} \mathrm{C}$ until mass loss associated with carbonates commences from $650-700^{\circ} \mathrm{C}$ (the association of this peak with carbonate minerals is due 


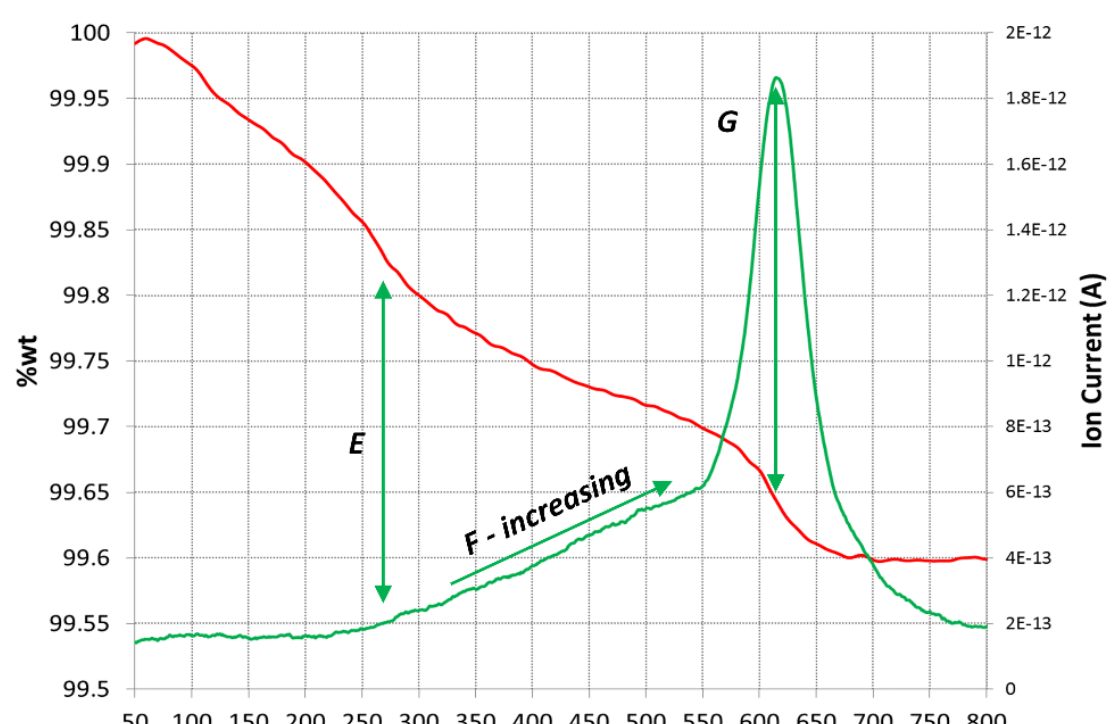

276

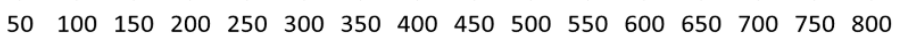

Figure 4: TG mass loss curve (red) and mass $44\left(\mathrm{CO}_{2}\right)$ mass spectrometry curve (green) for Esp. Events $E-G$ (see text) are highlighted.

279

280

281

282

283
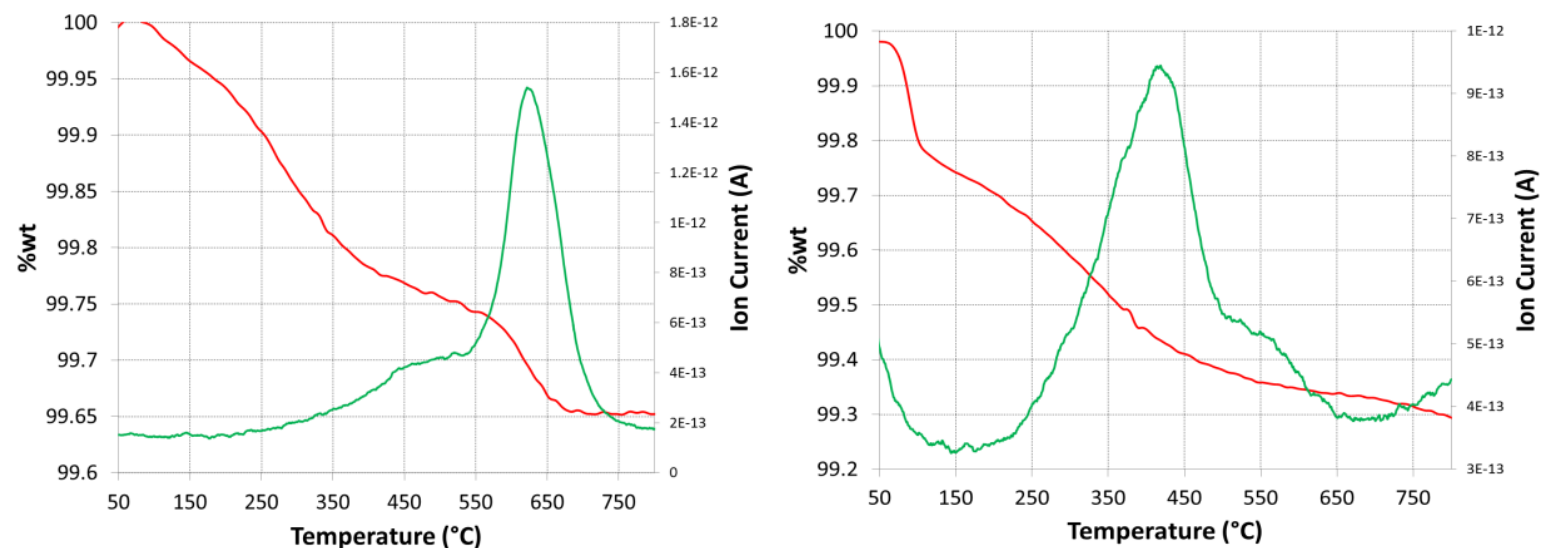

284

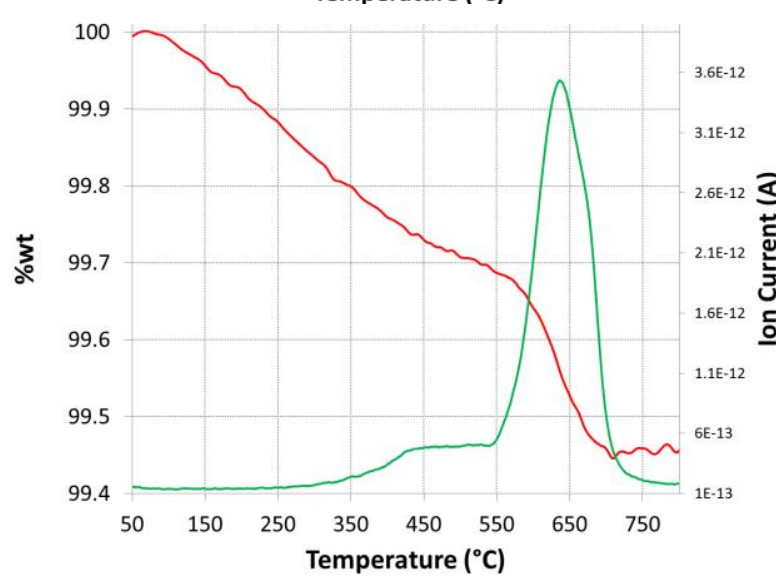

285

286

287

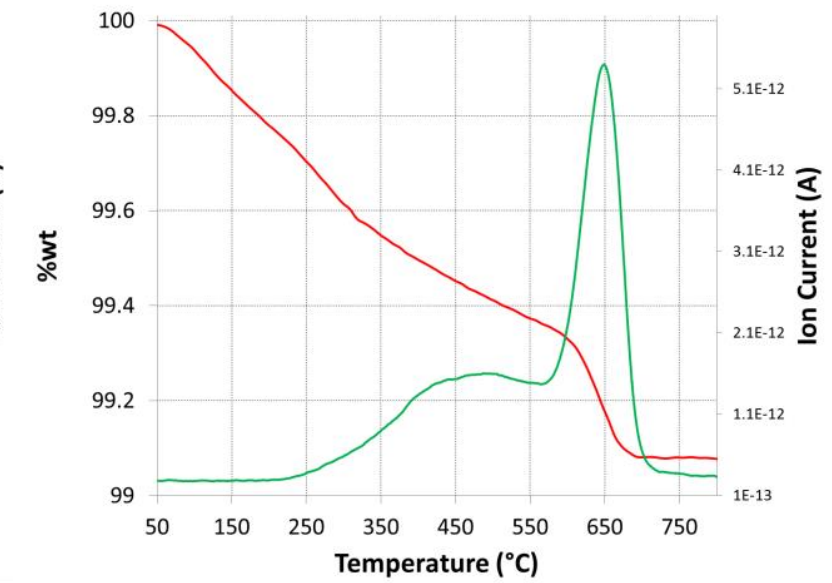

Figure 5: TG mass loss curves (red) and mass $44\left(\mathrm{CO}_{2}\right)$ mass spectrometry curves (green) for Ann (top left), 


\subsection{Carbon Content}

292 The results of carbon content analysis are provided in Figure 6, presented as \%wt C. It can be observed that that the magnitude and presence of carbon is not related to whether or not the sample was retrieved from a buried context.

Figure 6: Percentage weight of carbon removed from dating samples during firing at $130-500^{\circ} \mathrm{C}$. The retrieval of the sample from a buried context is indicated by (b).

The mass of organic matter (computed using $m_{c}$ and an OM/OC ratio of 1.95$), m_{o m}$, as a $\%$ of the total fractional mass loss, $m_{R H X C}$, of dating trial samples (Barrett 2015;2017a) is presented in Figure 7 (for $t^{1 / 4}$ model, similar levels for $t^{1 / n}$, see Figure 5 of Barrett 2017a). Levels of 5-20\% are common with some values also in the range 35-45\%.

The effect uncertainties in the $\mathrm{OM} / \mathrm{OC}$ multiplicative factor (1.4-2.5) have on the age estimates from dating trials are 2017a for details and Barrett 2015 for full set of curves). 
Table 4: Examples of the effect of uncertainties in OM/OC ratio (using 2.5 or 1.4) on the age range estimates. For $t^{1 / 4}$ and $t^{1 / n}$ model. Italicised and bold correspond to age ranges that overlap with known age.

Figure 7: The mass of organic matter (computed using $m_{c}$ and an OM/OC ratio of 1.95), $m_{o m}$, as a $\%$ of total fractional mass loss, $m_{R H x C}$, upon heating between $130^{\circ} \mathrm{C}$ and $500^{\circ} \mathrm{C}$. For $t^{1 / 4}$ model.

\begin{tabular}{|c|c|c|c|c|c|}
\hline & \multirow[b]{2}{*}{$\begin{array}{c}\text { Known } \\
\text { Age } \\
\text { (Yrs) }\end{array}$} & \multicolumn{2}{|c|}{$\begin{array}{l}\text { Age Range (Yrs) } \\
\text { (OM/OC) } t^{1 / 4}\end{array}$} & \multicolumn{2}{|c|}{$\begin{array}{l}\text { Age Range (Yrs) } \\
\text { (OM/OC) } t^{1 / n}\end{array}$} \\
\hline & & $\begin{array}{c}\text { OM/OC } \\
(2.5)\end{array}$ & $\begin{array}{l}\mathrm{OM} / \mathrm{OC} \\
(1.4)\end{array}$ & $\begin{array}{c}\text { OM/OC } \\
(2.5)\end{array}$ & $\begin{array}{c}\text { OM/OC } \\
(1.4)\end{array}$ \\
\hline Ann & $110 \pm 14$ & 319 & 1283 & 59 & 182 \\
\hline Esp & $141 \pm 6$ & 147 & 452 & 284 & 1115 \\
\hline Nic & $398 \pm 2$ & 46440 & 66885 & 820437 & 1267480 \\
\hline Mac & $228 \pm 2$ & 477321093 & 642239904 & 8113299 & 10271317 \\
\hline Ria & $339 \pm 25$ & 122179 & 191242 & 4150 & 5660 \\
\hline Rat & $245 \pm 2$ & 1415987 & 2145539 & 4343 & 5517 \\
\hline Cal & $182 \pm 9$ & 2337 & 3014 & 177 & 212 \\
\hline Joy & $412 \pm 2$ & 321 & 489 & 152 & 208 \\
\hline Cau & $399 \pm 4$ & 388 & 704 & -- & -- \\
\hline Bel & $395 \pm 3$ & 258 & 2178 & 774 & 17058 \\
\hline Tur & $229 \pm 35$ & 36508 & 62139 & 359 & 494 \\
\hline Ted & $339 \pm 25$ & 174 & 263 & 16 & 21 \\
\hline
\end{tabular}



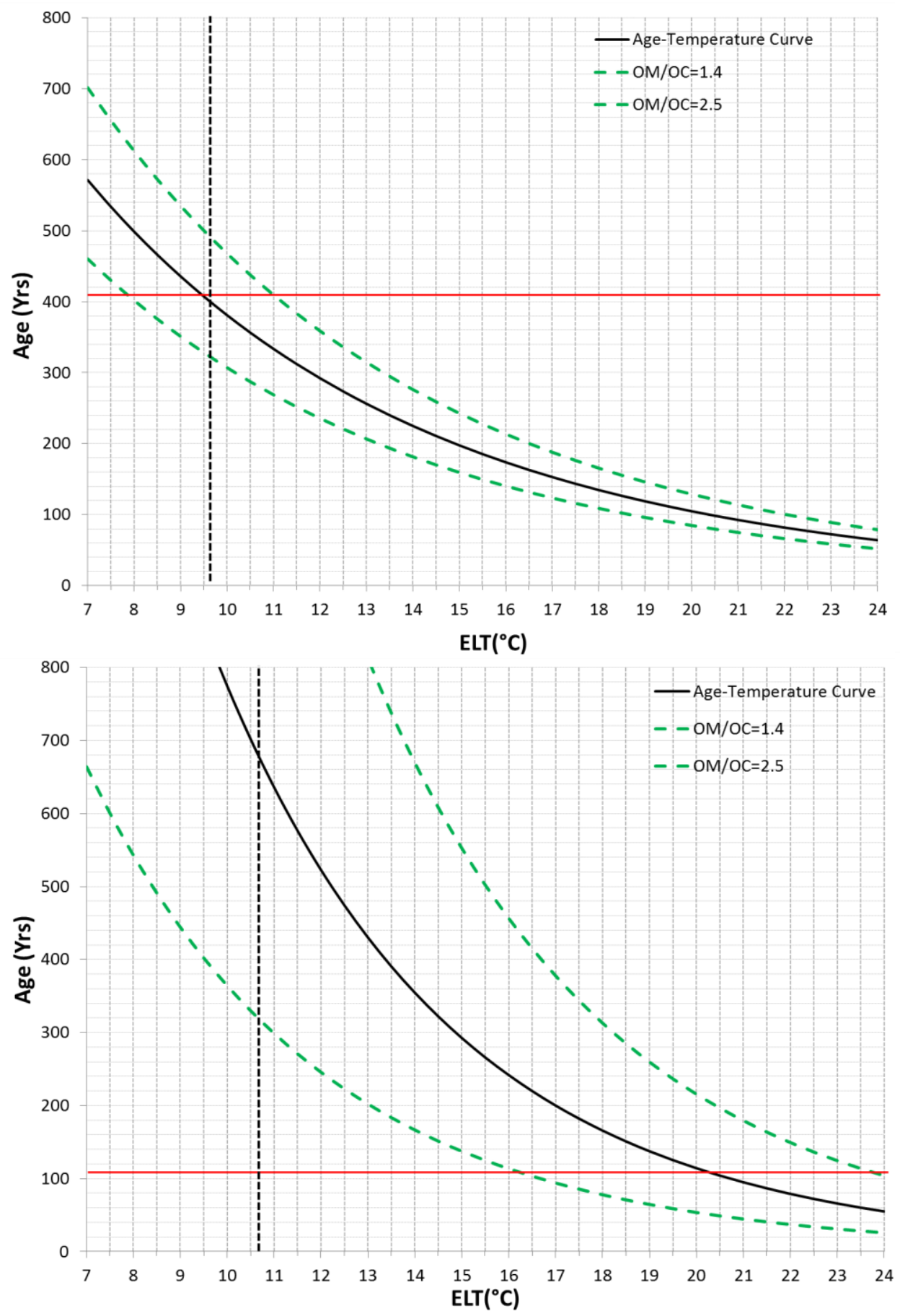

Figure 8: Effect of uncertainties in $\mathrm{OM} / O C$ ratio (1.4-2.5, green dash) on the age temperature curves of Joy (top) and Ann (bottom). Red line is known age. Black dashed line is ELT estimate. Using a $t^{1 / 4}$ model. 


\section{$3.4 \quad$ FTIR/XRD}

\subsubsection{Reheating Mineral Alteration}

351 The complete collection of spectra with tables of peak and mineral identification for all samples using both XRD and

352 FTIR are provided in Barrett (2015). With the exception of two samples, Mac and Bel, the spectra from XRD and

353 FTIR showed no signs of mineral alteration associated with reheating, see Figure 9 for Ann for the typical level of

354 similarity in the reheated and non-reheated spectra.

355

356

357

358

359

360

361

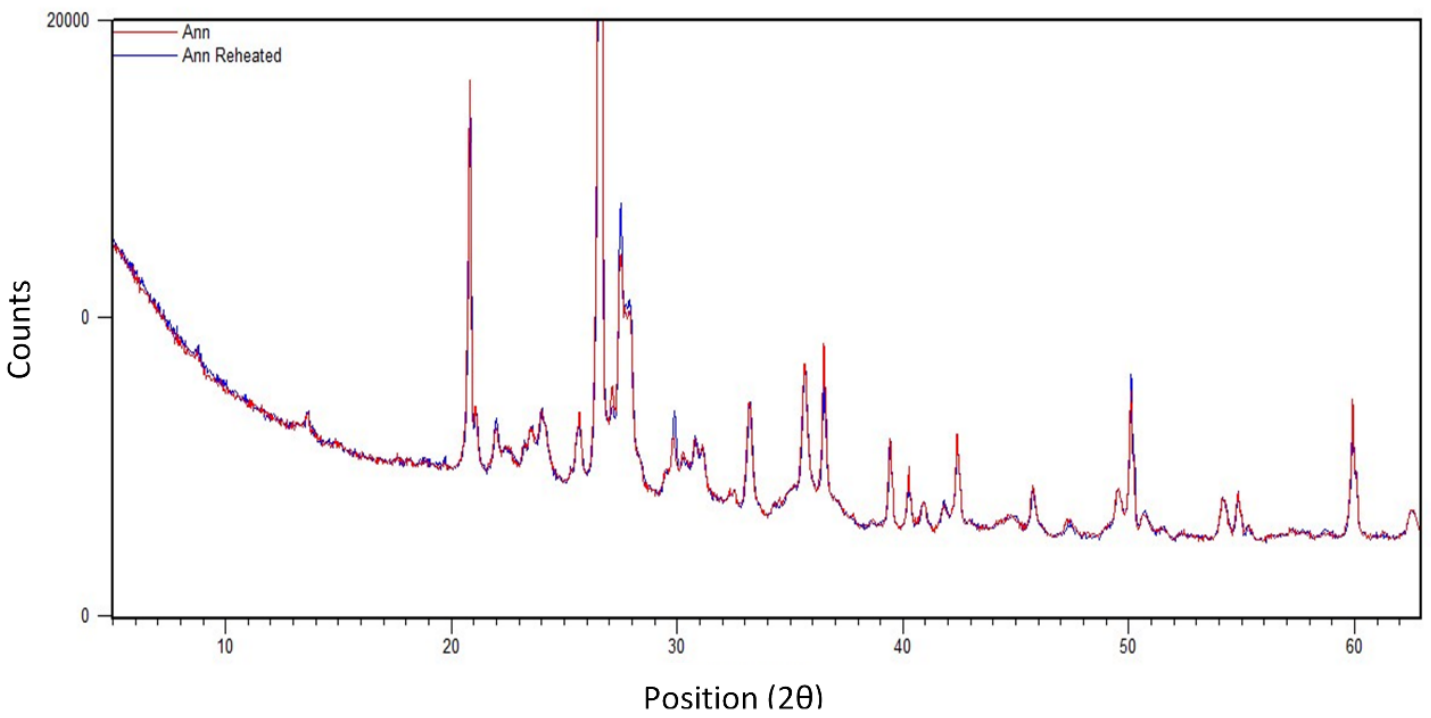

362

363

364

365

366

367

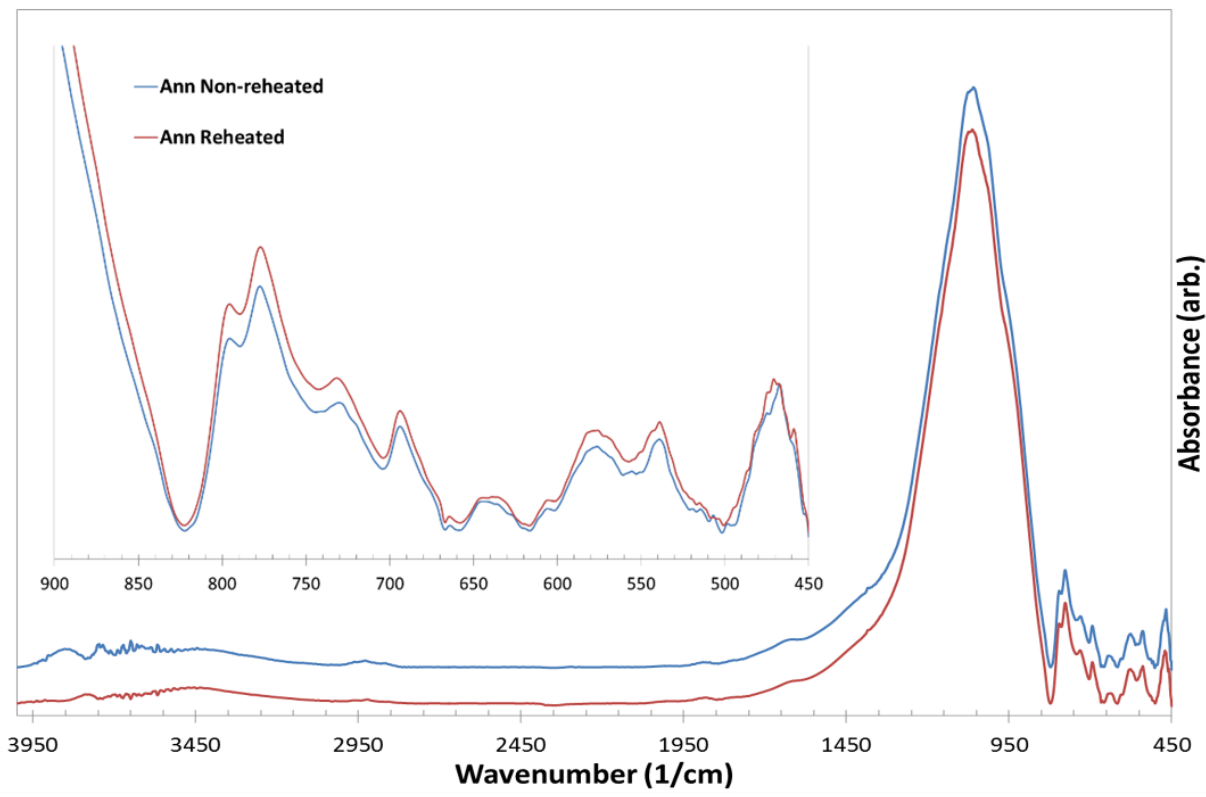

Figure 9: XRD (top) and FTIR (bottom) Spectra of non-reheated and reheated Ann sample. Inset of the region $450-900 \mathrm{~cm}^{-1}$ used in mineral identification. 
371 Two samples, Mac and Bel, displayed significant differences in spectra, with Figure 10 (top) for Mac representative 372 of the major XRD differences observed in Bel also. For Mac, the XRD spectrum of non-reheated sample has peaks 373 at $14.7^{\circ}, 29.7^{\circ}$ and $31.8^{\circ}(2 \theta)$ that are either non-existent or very weak in the reheated sample spectrum, whereas the 374 reheated sample spectrum has peaks at $25.4^{\circ}, 38.6^{\circ}, 48.6^{\circ}$ and $52.3^{\circ}(2 \theta)$ that are either non-existent or significantly 375 weaker in the non-reheated sample. The former non-reheated peaks have been identified as bassanite (hemihydrate) 376 reflections and the latter reflections in the reheated samples are attributed to anhydrite (using ICDD PDF2 peak 377 identification library). Differences in the two spectra are attributed to the level of hydration of sulfates within the 378 ceramic. For $\mathrm{Bel}$, there are strong differences in the non-reheated and reheated spectra. The following peaks are 379 present in the non-reheated and either absent or very low-level in the reheated sample: $14.6^{\circ}, 29.6^{\circ}, 31.8^{\circ}(2 \theta)$. These can all be identified with bassanite (hemihydrate). For the reheated sample, peaks not present in the non-reheated sample are: $24.1^{\circ}(2 \theta), 25.4^{\circ}(2 \theta), 31.3^{\circ}(2 \theta), 38.6^{\circ}(2 \theta), 40.8^{\circ}(2 \theta)$ and $41.6^{\circ}(2 \theta)$. These can all be identified with anhydrite. The differences are similar to those recorded for Mac.

383 This is supported by the FTIR spectra, shown for Mac in Figure 10 (bottom) and representative of the differences 384 observed for Bel. There are some significant differences between the non-reheated and reheated Mac samples. The reheated sample has peaks at $575 \mathrm{~cm}^{-1}$ and $614 \mathrm{~cm}^{-1}$ that are either very weak or not present in the non-reheated samples 386 as well as a peak at $677 \mathrm{~cm}^{-1}$ that appears to be greater in magnitude and shifted from $673 \mathrm{~cm}^{-1}$ in the non-reheated 387 sample. The non-reheated sample has a peak at $633 \mathrm{~cm}^{-1}$ that is not present in the reheated sample together with the 388 previously mentioned shifted peak at $673 \mathrm{~cm}^{-1}$. The following minerals can be attributed to the aforementioned peaks: 389 Anhydrite $=575,614,617,673,677 \mathrm{~cm}^{-1}$; Bassanite $=633 \mathrm{~cm}^{-1}$. The change upon reheated is associated with 390 dehydration of sulfates (gypsum).

391 For $B e l$, peaks at $663 \mathrm{~cm}^{-1}, 669 \mathrm{~cm}^{-1}$ and $1154 \mathrm{~cm}^{-1}$ in the non-reheated samples are consistent with bassanite, gypsum 392 and bassanite, respectively. Peaks at $613 \mathrm{~cm}^{-1}$ and $678 \mathrm{~cm}^{-1}$ in the reheated sample are attributed to anhydrite. There 393 are no other significant differences between the spectra aside from those associated with variations in adsorbed 394 moisture and atmospheric carbon dioxide. 


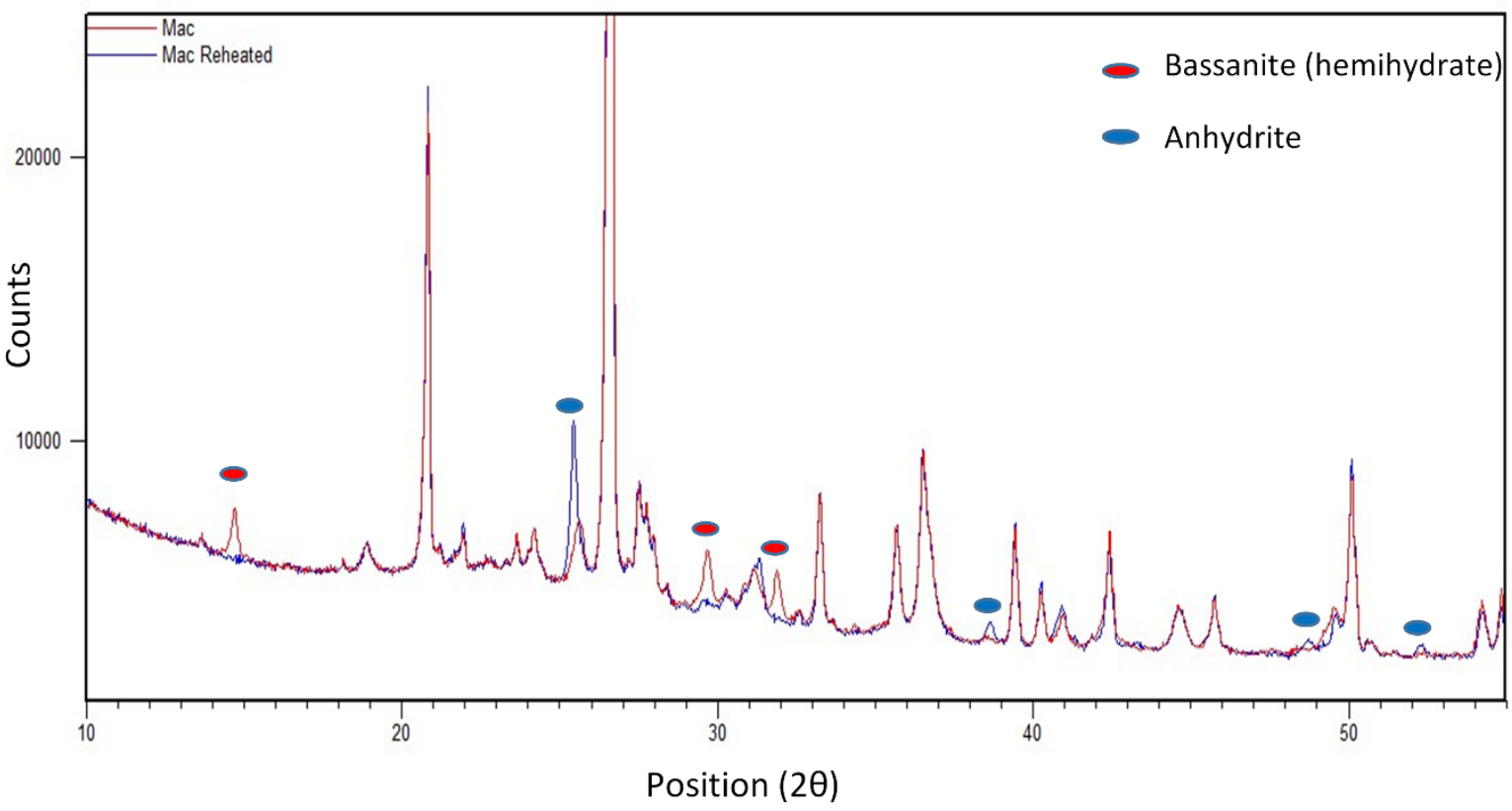

405

406

-Mac Non-reheated

-Mac Reheated

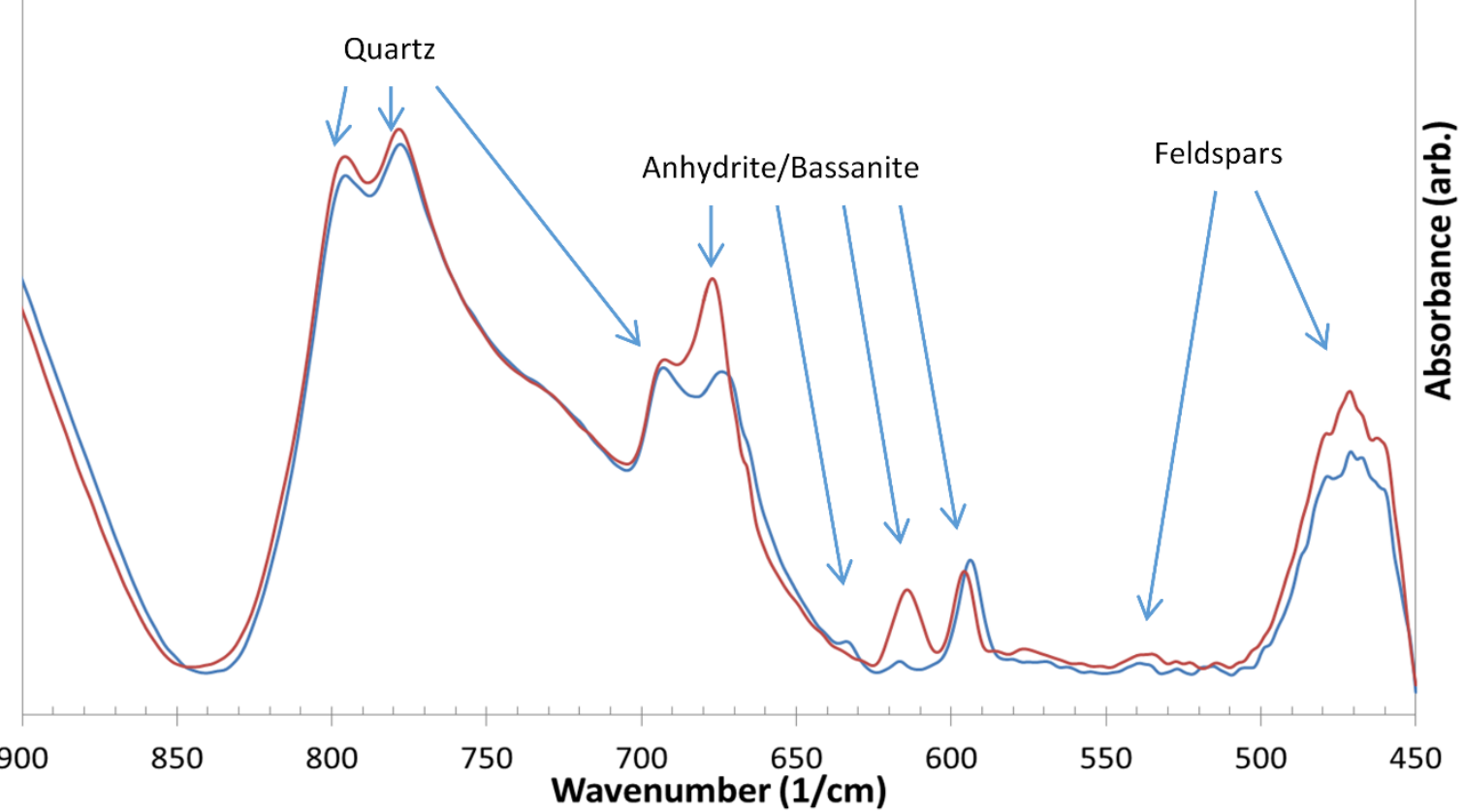

Figure 10: Top - XRD spectra of Mac sample without (red) and with (blue) reheating at $500^{\circ} \mathrm{C}$. Region constrained to $10-55^{\circ}(2 \theta)$. Red ovals mark basanite (hemihydrate) peaks; blue ovals mark anhydrite peaks. Bottom - FTIR spectra of non-reheated (blue) and reheated (red) Mac sample over the region 450$900(1 / \mathrm{cm})$. Gypsum associated peaks (anhydrite/bassanite) are highlighted together with some examples of quartz and feldspars. 


\subsubsection{TG-MS Gypsum}

420

421

422

423

424

425

426

427

428

429

430

431

432

433

434

435

436

437

438

439

440

The TG-MS measurements provided evidence for release of $\mathrm{SO}_{2}$ only for samples $\mathrm{Mac}$ and Bel, see Figure 11 for Bel, and with an onset above $650-700^{\circ} \mathrm{C}$.

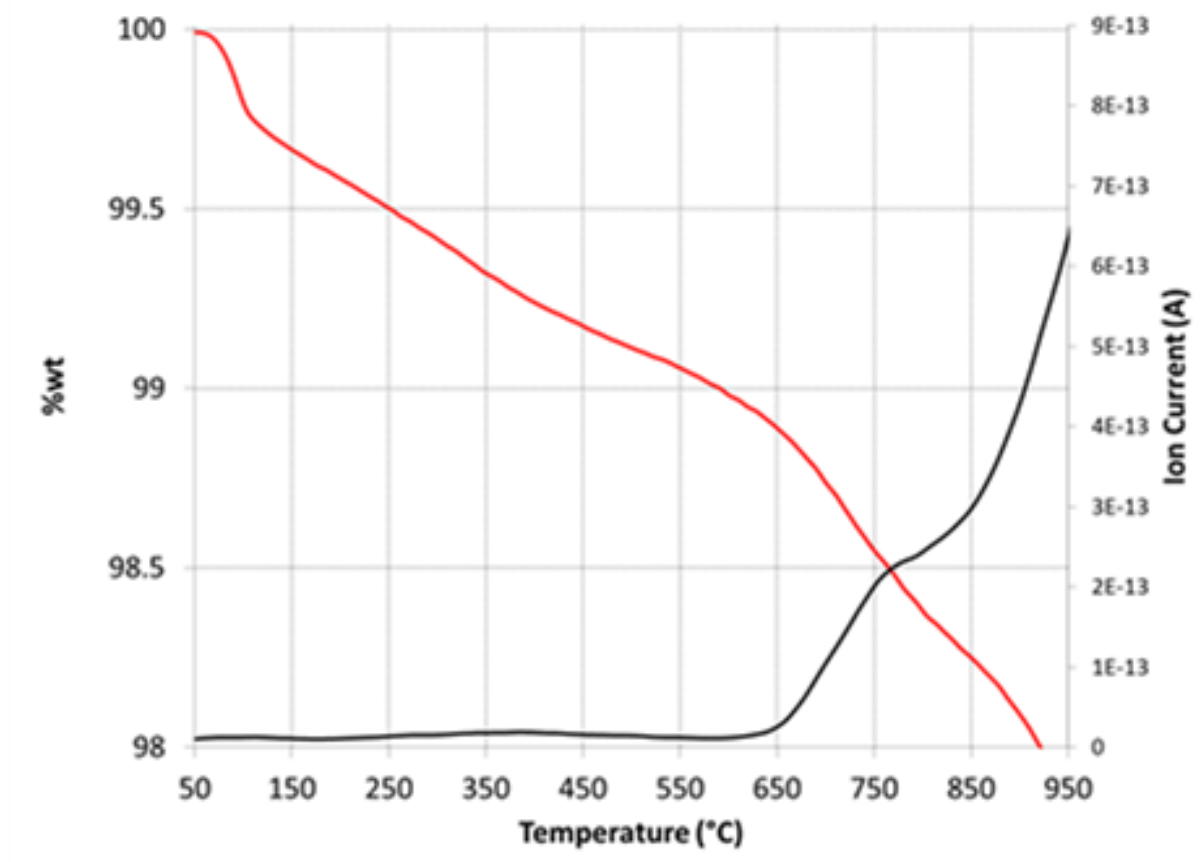

Figure 11: TG mass loss curve (red) and mass $64\left(\mathrm{SO}_{2}\right)$ mass spectrometry curve (black) for Bel.

\subsubsection{Stage 1 Behaviour}

Dealt with in Barrett $(2015$; 2017b) but of relevance to the present work are the Stage 1 (S1) portion of mass gain curves obtained following drying $\left(130^{\circ} \mathrm{C}\right)$ and reheating $\left(500^{\circ} \mathrm{C}\right)$ of samples. Stage 1 corresponds to the initial and more rapid mass gain that occurs following drying/reheating and is attributed to physisorption-related processes (Barrett 2015; 2017b); Stage 1 commences with exposure of the ceramic to moisture in the air and is considered complete with the commencement of Stage 2, i.e. when the mass gain curve is adequately modelled by a $t^{1 / n}$ or $t^{1 / 4}$ model alone. For most samples, the magnitude of mass gain in this stage was very similar following both drying, $m_{S 1-130}$, and reheating, $m_{S 1-500}$; however, for $\mathrm{Mac}$ and $\mathrm{Bel}$, there were considerable differences, see Figure 12 for Mac. The magnitudes (fractional) are provided in Table 5 with a difference of the order of $\sim 4$ evident. 


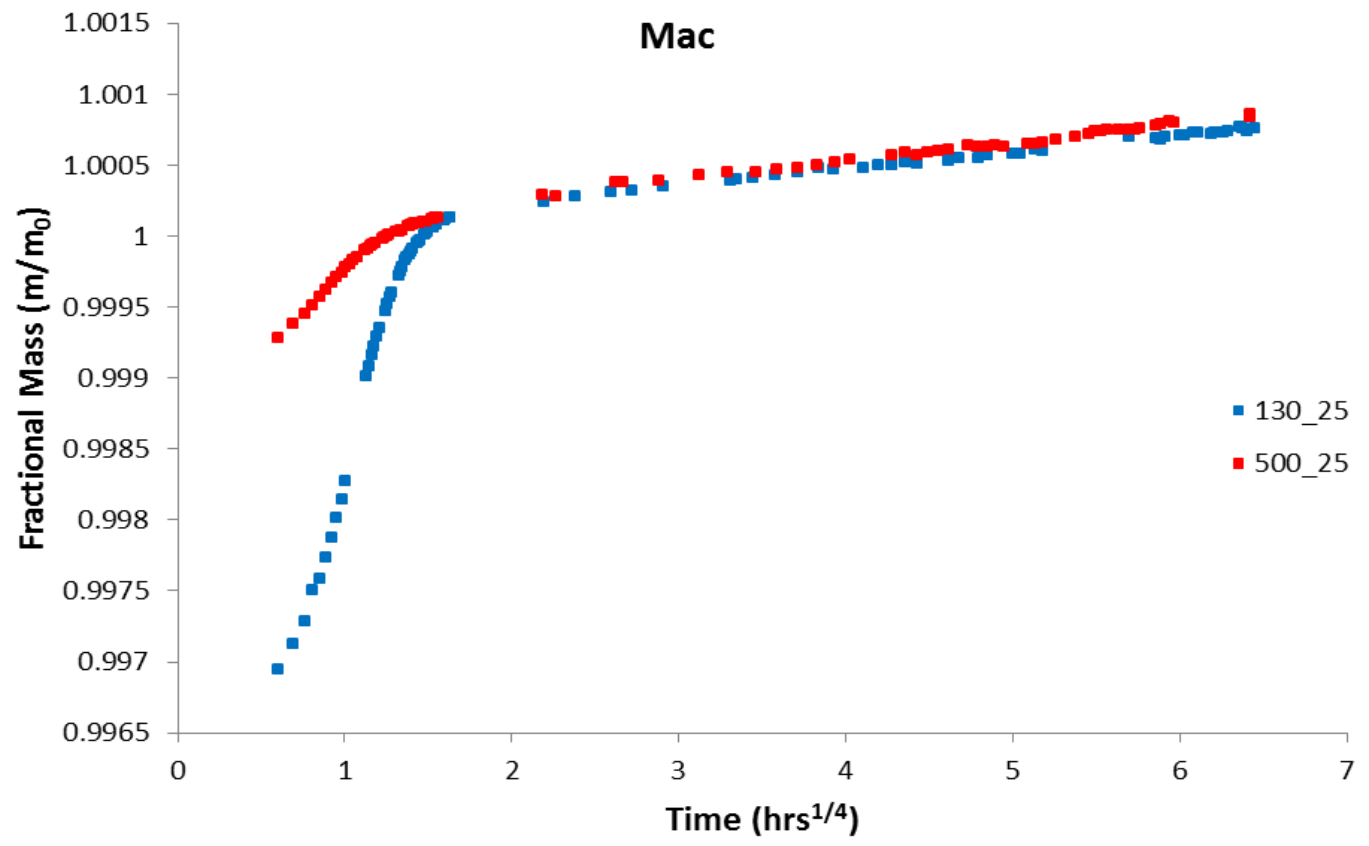

452

Figure 12: Fractional mass gain curves, displaying the Stage 1 region, of Mac sample. Sample aging at $25^{\circ} \mathrm{C}$ following heating at $130^{\circ} \mathrm{C}$ (blue) and $500^{\circ} \mathrm{C}$ (red). Normalised relative to the Stage 2 modelled intercept mass for display purposes.

454

Table 5: Stage 1 fractional mass for $130 \mathrm{C}$ and $500 \mathrm{C}$ components $\left(25^{\circ} \mathrm{C}\right.$ aging) together with the ratio of the two. For the $t^{1 / 4}$ model (see Barrett 2015 for the method).

\begin{tabular}{|c|c|c|c|}
\hline $\boldsymbol{t}^{\mathbf{1 / 4}}$ & $\boldsymbol{m}_{\boldsymbol{S 1 - 1 3 0}}$ & $\boldsymbol{m}_{\boldsymbol{S 1 - 5 0 0}}$ & $\boldsymbol{m}_{\boldsymbol{s 1 - 1 3 0}} / \boldsymbol{m}_{\boldsymbol{s 1 - 5 0 0}}$ \\
\hline Mac & 0.0030745 & 0.0007159 & 4.30 \\
\hline Bel & 0.0048373 & 0.0012858 & 3.76 \\
\hline
\end{tabular}




\subsubsection{Organics FTIR}

462 The results of analysis of the region $2800-3000 \mathrm{~cm}^{-1}$ for organics are presented in Table 6, and Figures 13-15. Table

4636 presents, for all samples and for reheated and non-reheated spectra, the peak positions $\left(\mathrm{cm}^{-1}\right)$ and a subjective

464 assessment of the strength of those peaks. It also attempts to group the observed peaks. Figure 13 is a typical example

465 of the spectra in the region of interest, $2800-3000 \mathrm{~cm}^{-1}$. Figure 14 presents the peak position and their possible ranges

466 as a function of wavenumber for non-reheated and reheated samples. Using the peak position ranges in Figure 14,

467 the number of samples with organic peaks at wavenumbers from $2840-2980 \mathrm{~cm}^{-1}$ is presented in Figure 15 . This data

468 is smoothed with a running average of $n=9\left(\mathrm{~cm}^{-1}\right)$.

469

470

471

472

473

474

475

476

477

478

479

480

481

482

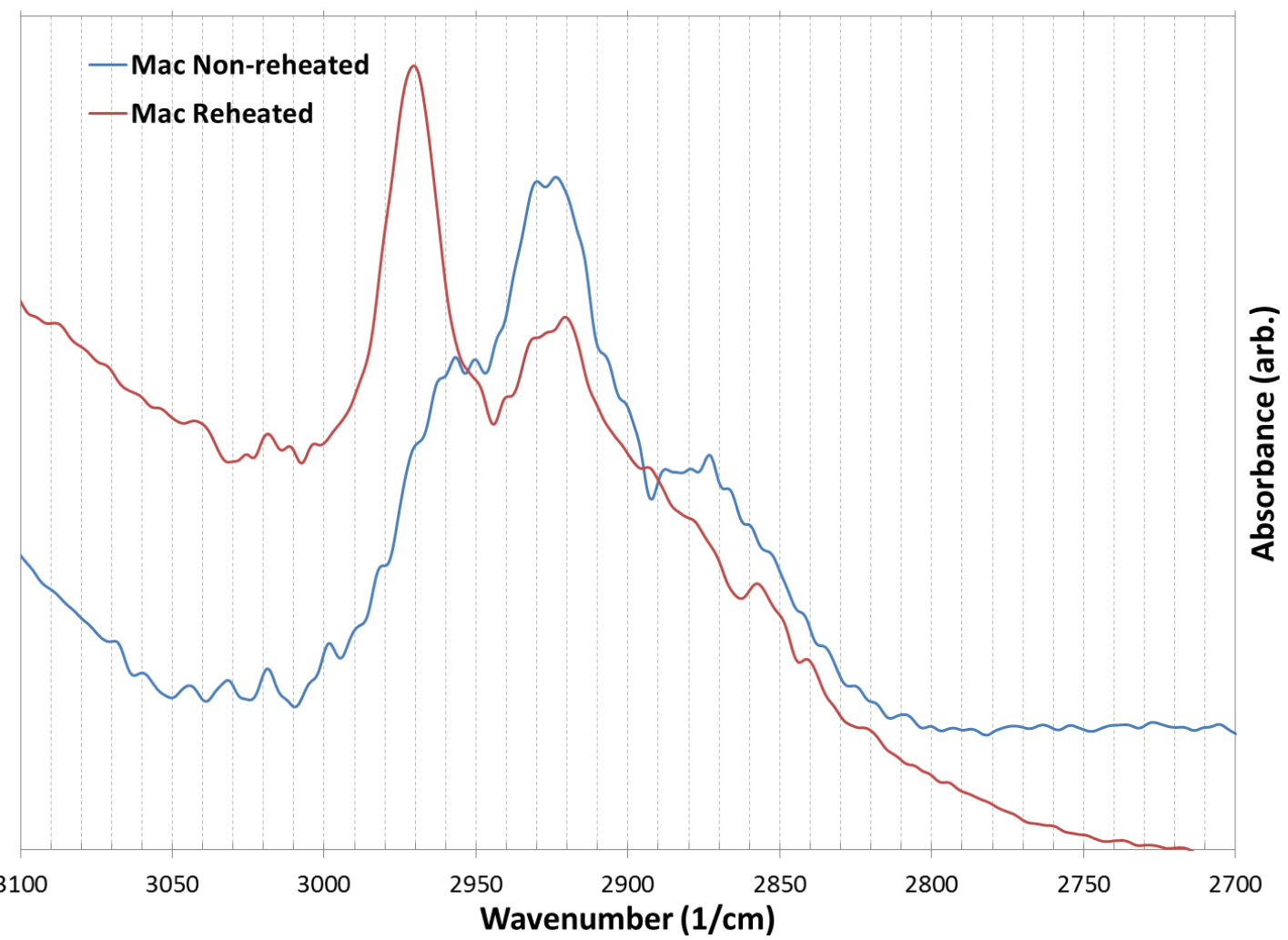

Figure 13: FTIR spectra across region of interest in organic identification for Mac (non-reheated and reheated). Peaks in the ranges $2850-2860 \mathrm{~cm}^{-1}, 2920-2930 \mathrm{~cm}^{-1}, 2950-2970 \mathrm{~cm}^{-1}$ are typical for most samples. 


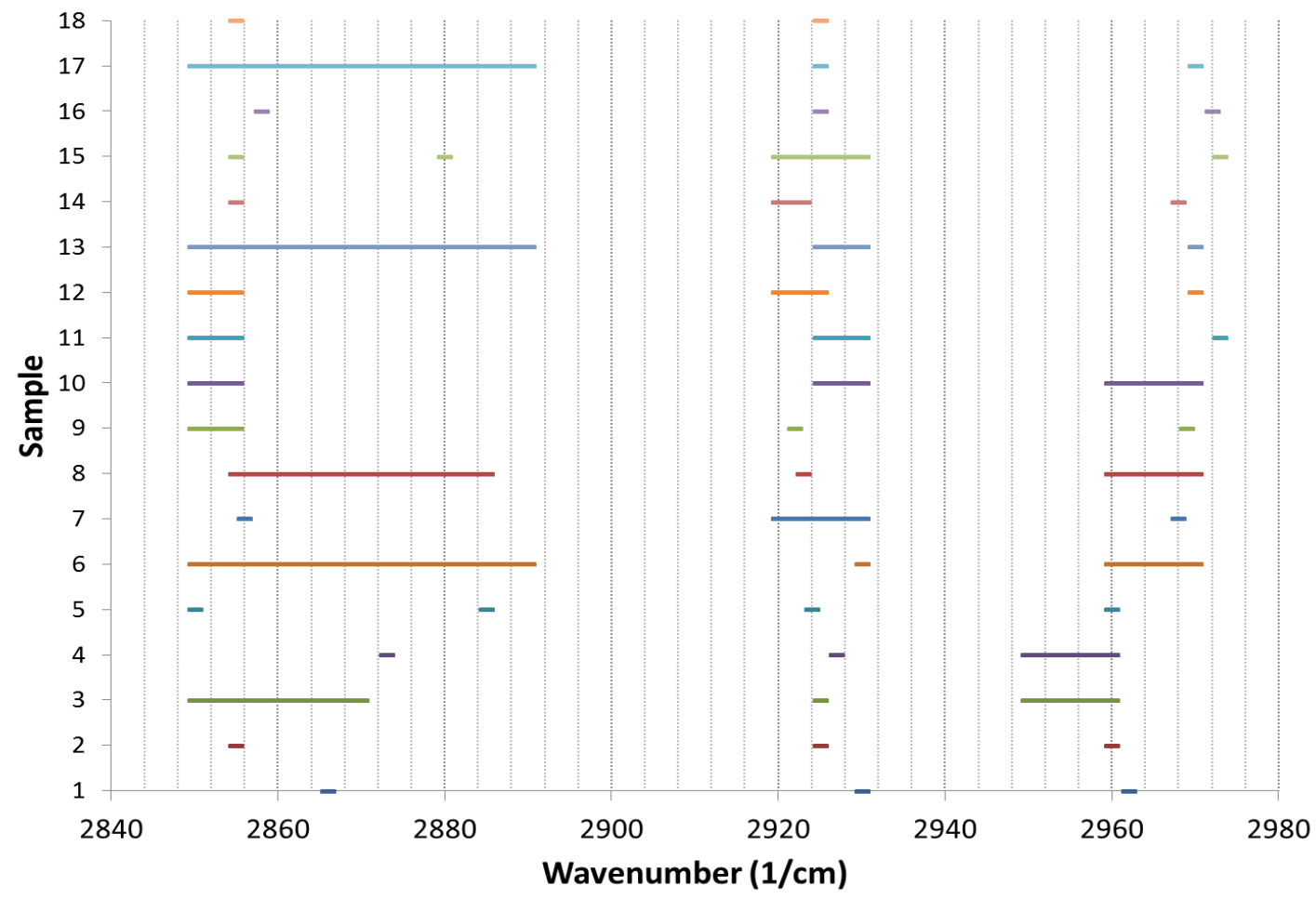

499

500

501

502

503

504

505

506

507

508

509

510

511

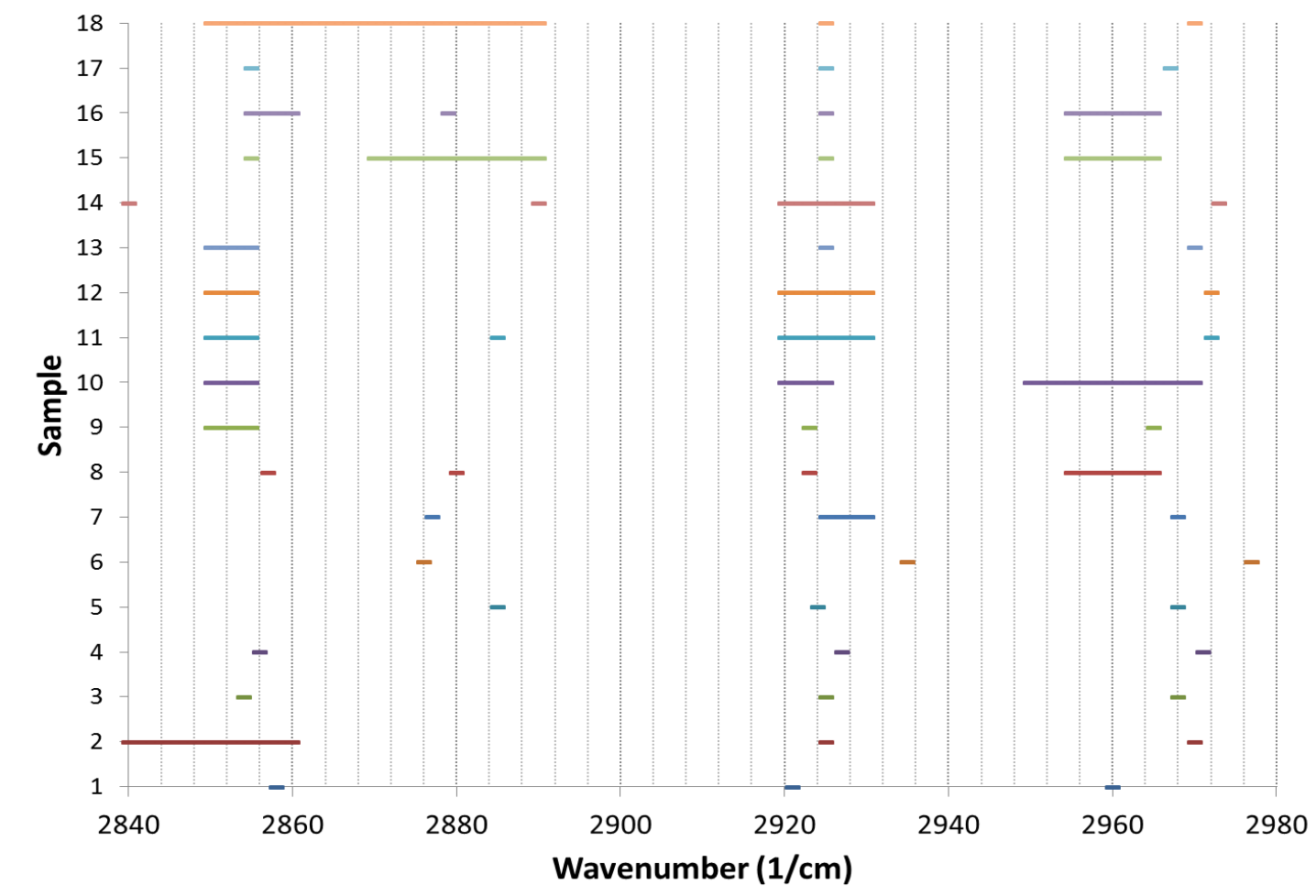

512

Figure 14: Peak positions of organics in non-reheated (top) and reheated (bottom) samples, see Table 6. Sample numbers correspond as follows: (1) Ann, (2) Esp, (3) Nic, (4) Mac, (5) Ria, (6) Etr, (7) Rom, (8) Por,

513 (9) Rat, (10) Cal, (11) Lan, (12) Joy, (13) Cau, (14) Bel, (15) Dow1, (16) Dow2, (17) Tur, (18) Ted. 
516

517

518

Table 6: FTIR peaks positions in organics regions $2800-3000 \mathrm{~cm}^{-1}$ for dating samples, both non-reheated and reheated. Colour denotes relative strength of peaks: green=weak; gold=moderate; red=strong. Average values and standard deviations are based on midpoints of ranges.

\begin{tabular}{|c|c|c|c|c|c|c|c|c|}
\hline & \multicolumn{4}{|c|}{ Non-Reheated } & \multicolumn{4}{|c|}{ Reheated } \\
\hline Ann & 2866 & & 2930 & 2962 & 2858 & & 2921 & 2960 \\
\hline Esp & 2855 & & 2925 & 2960 & $2840-2860$ & & 2925 & 2970 \\
\hline Nic & $2850-2870$ & & 2925 & $2950-2960$ & 2854 & & 2925 & 2968 \\
\hline Mac & 2873 & & 2927 & $2950-2960$ & 2856 & & 2927 & 2971 \\
\hline Ria & 2850 & 2885 & 2924 & 2960 & & 2885 & 2924 & 2968 \\
\hline Etr & $2850-2890$ & & 2930 & $2960-2970$ & & 2876 & 2935 & 2977 \\
\hline Rom & 2856 & & $2920-2930$ & 2968 & & 2878 & $2925-2930$ & 2968 \\
\hline Por & $2855-2885$ & & 2923 & $2960-2970$ & 2857 & 2880 & 2923 & $2955-2965$ \\
\hline Rat & $2850-2855$ & & 2922 & 2969 & $2850-2855$ & & 2923 & 2965 \\
\hline Cal & $2850-2855$ & & $2925-2930$ & $2960-2970$ & $2850-2855$ & & $2920-2925$ & $2950-2970$ \\
\hline Lan & $2850-2855$ & & $2925-2930$ & 2973 & $2850-2855$ & 2885 & $2920-2930$ & 2972 \\
\hline Joy & $2850-2855$ & & $2920-2925$ & 2970 & $2850-2855$ & & $2920-2930$ & 2972 \\
\hline Cau & $2850-2890$ & & $2925-2930$ & 2970 & $2850-2855$ & & 2925 & 2970 \\
\hline Bel & 2855 & & $2920-2923$ & 2968 & 2840 & 2890 & $2920-2930$ & 2973 \\
\hline Dow1 & 2854 & 2880 & $2920-2930$ & 2973 & 2855 & $2970-2890$ & 2925 & $2955-2965$ \\
\hline Dow2 & 2858 & & 2925 & 2972 & $2855-2860$ & 2879 & 2925 & $2955-2965$ \\
\hline Tur & $2850-2890$ & & 2925 & 2970 & 2855 & & 2925 & 2967 \\
\hline Ted & 2855 & & 2925 & 2965 & $2850-2890$ & & 2925 & 2970 \\
\hline Avg. & 2859.5 & 2882.5 & 2925.4 & 2965.8 & 2855.3 & 2881.9 & 2925.2 & 2967.3 \\
\hline $\begin{array}{l}\text { Std. } \\
\text { Dev. }\end{array}$ & 7.7 & 2.5 & 2.5 & 5.4 & 5.9 & 4.9 & 2.8 & 5322 \\
\hline
\end{tabular}




\section{Discussion}

\section{$547 \quad 4.1 \quad$ Incomplete Drying}

548 Two models (power-based and exponential-based) were applied to the drying mass loss curves, Figure 1, with the

549 quality of the regressions quite variable, Table 1. Differences between the goodness-of-fits of both models are minor

550 and do not provide clear support for the selection of either. A better distinction might be made with improved quality 551 data; however, this issue with prolonged drying was unexpected when the experiment was designed. Control of 552 environmental conditions during removal from the oven for weighing was inadequate to prevent large fluctuations in 553 the mass, associated with the level of physisorption taking place; this is reflected in the RMSE values of the models, 554 Table 1, where samples with high surface area (Etr, Rom, Por, Lan, see Table S.3) have the largest fluctuations, see 555 for example Figure 1 for Lan.

556 The correlation of the modelled remaining mass of loose water with properties with which it would be expected to be 557 associated, for example surface area and pore volume, was examined, Table 2; these results favour the exponential 558 model.

559 The exponential model was ultimately selected for the reasons above and also because the power-based model was 560 problematic; for a number of samples, the modelled mass of remaining loose water exceeded the mass loss estimates 561 due to heating at $500^{\circ} \mathrm{C}$, and for several samples regressions using the power-based model produced parameter values 562 that were nonsensical (i.e. a final 'dry' mass that exceeded the initial mass of the drying curve). As well as this, the 563 use of a power model was motivated by a $t^{1 / 2}$ behaviour suggested by Brosnan and Robinson (2003); however, the 564 model could only be successfully applied with the power constraint relaxed ( $1 / n$ instead). The exponential model is 565 more satisfactory in its interpretation, with the rate of moisture removal being proportional to the level of moisture 566 remaining.

567 While the exponential model was selected for use, the authors emphasises that this was borne out of pragmatism and 568 the appropriateness of this model clearly requires more investigation; the quality of the fits produced, Figure 1, were 569 less than satisfactory, and the confidence intervals were also very large, for example Figure 2. Nonetheless, its use 570 was deemed the only way to proceed. That the modelled remaining loose water was generally greatest for the high 571 surface area samples, Figure 2 and see Table S.3, is somewhat reassuring and would also explain the greater correlation 
572 of this model with the surface area, pore volume and TG-MS data, Table 2, the inference being that for high surface

573 area samples a significant quantity of physisorbed water is possibly still being removed when heated at $500^{\circ} \mathrm{C}$.

574 Table 7: Summary of the drying conditions and presence of drying data in the literature.

\begin{tabular}{|c|c|c|c|c|}
\hline Publication & $\begin{array}{l}\text { Sample } \\
\text { Size }\end{array}$ & $\begin{array}{l}\text { Drying } \\
\text { Temp. }\left({ }^{\circ} \mathrm{C}\right)\end{array}$ & Duration of Drying & $\begin{array}{l}\text { Drying Data } \\
\text { Presented (Y/N) } \\
\text { (other drying proxy } \\
\text { data) }\end{array}$ \\
\hline Wilson et al. (2009) & $3-5 g$ & 105 & $\begin{array}{l}\text { Not specified } \\
\text { (to constant mass) }\end{array}$ & $\mathrm{N}$ \\
\hline Bowen et al. (2011) & $\begin{array}{l}\text { 32-96g } \\
\text { (sherd) }\end{array}$ & 110 & $\begin{array}{l}\text { 20-30hrs } \\
\text { (However, incomplete drying after } \\
2 \text { weeks) }\end{array}$ & $\mathrm{Y}$ \\
\hline Wilson et al. (2012) & $0.5-4.0 \mathrm{~g}$ & 105 & $\begin{array}{l}\text { To constant mass } \\
\text { ('few hours' to 'several days') }\end{array}$ & $\mathrm{N}$ \\
\hline Bowen et al. 2013 & $1-2 g$ & 110 & 30-50hrs & $\mathrm{N}$ \\
\hline $\begin{array}{l}\text { Burakov and } \\
\text { Nachasova (2013) }\end{array}$ & $1-15 g$ & 105 & $12 \mathrm{hrs}$ & $\mathrm{N}$ \\
\hline $\begin{array}{l}\text { Le Goff and Gallet } \\
\text { (2014) }\end{array}$ & $2-3 g$ & 105 & $\begin{array}{l}4 \text { and } 16 \mathrm{hrs} \text { for one group } \\
66 \text { and } 51 \mathrm{hrs} \text { for one group } \\
\text { Issue with duration of raised, } \\
\text { additional mass loss with } \\
\text { repeated heating }\end{array}$ & $\begin{array}{l}\mathrm{N} \\
\text { (Mass gain curves } \\
\text { demonstrating } \\
\text { variation in mass level } \\
\text { with drying temp. } \\
95 / 105^{\circ} \mathrm{C} \text { and } \\
\text { duration) } \\
\end{array}$ \\
\hline $\begin{array}{l}\text { Le Goff and Gallet } \\
\text { (2015a) }\end{array}$ & $2-3 g$ & 105 & $11 \mathrm{hrs}$ and 14 days & $\begin{array}{l}\mathrm{N} \\
\text { (Mass gain curves } \\
\text { demonstrating } \\
\text { increase in mass gain } \\
\text { rate }\left(t^{1 / 4}\right) \text { with } \\
\text { prolonged drying) }\end{array}$ \\
\hline Numrich et al. (2015) & $2-4 g$ & 110 & $48 \mathrm{hrs}$ & $\mathrm{N}$ \\
\hline $\begin{array}{l}\text { Gallet and Le Goff } \\
(2015)\end{array}$ & $1.46-3 \mathrm{~g}$ & $\begin{array}{l}60,85,105 \\
130\end{array}$ & $\begin{array}{l}5 \text { hrs at } 60,85,105,130^{\circ} \mathrm{C} \\
23 \mathrm{hrs} \text { at } 105^{\circ} \mathrm{C} \\
246 \mathrm{hrs} \text { at } 105^{\circ} \mathrm{C}\end{array}$ & $\begin{array}{l}\mathrm{N} \\
\text { (Mass gain curves } \\
\text { demonstrating extra } \\
\text { loss in mass as a } \\
\text { function of heating } \\
\text { temperature and } \\
\text { additional heating } \\
\text { duration, with effects } \\
\text { on mass gain } \\
\text { behaviour also } \\
\text { evident) }\end{array}$ \\
\hline Zhao et al. 2015 & $0.4-1 \mathrm{~g}$ & $\begin{array}{l}110 \\
300 \\
\end{array}$ & $\begin{array}{l}5-7 \text { days at } 110^{\circ} \mathrm{C} \\
\text { Overnight at } 300^{\circ} \mathrm{C}\end{array}$ & $\mathrm{N}$ \\
\hline
\end{tabular}


576 For all samples, excluding Esp, drying was incomplete after 60 days, Figure 2, with the potential for considerable 577 quantities of moisture to be removed with additional drying, typically $0.25-1.5 \%$ of the total mass lost during reheating 578 at $500^{\circ} \mathrm{C}$, Figure 3. This poses potential issues for dating estimations where it is necessary to estimate the rehydroxyl 579 mass loss, $m_{R H X}$, during heating at $500^{\circ} \mathrm{C}$. If, say, up to $2 \%$ of this mass estimate is actually loosely bound physisorbed water, $m_{l w}$, that has not been recognized or poorly accounted for, then a discrepancy in the age estimate of 581 approximately $8 \%$ of the age estimate can result (i.e. if there is an uncertainty, $d m$, in the mass, $m$, then the uncertainty, $582 d t$, in the age estimate, $t$, is given by $\left.(t+d t) / t=((m+d m) / m)^{4}\right)$. For the associated dating trial (Barrett 2017a), the estimated $m_{l w}$ was taken account of using the results presented in the present work. There are clearly large uncertainties 584 in this estimation, on account of the quality of the data and uncertainty in the model used. Nonetheless, even permitting $585 m_{l w}$ to contribute a maximum of $4 \%$ of the total mass loss, the result is only a $17 \%$ discrepancy in the age estimate and this, unfortunately, is still only a minor contributor to the significant discrepancies observed in age estimates (Barrett 587 2017a, see also Table 4). Ignoring the results of the dating trial, if all other issues could be removed, then uncertainties 588 of this magnitude alone would be problematic for the validation and use the method.

Prolonged drying is clearly an issue for RHX dating; its possible presence in previous work was examined, with the conditions of drying and evidence for constant mass or long drying times summarised in Table 7. For the majority of 591 these studies, samples were dried either at $105-110^{\circ} \mathrm{C}$ until they reached constant mass (Wilson et al. 2009; 2012) or 592 for a fixed duration expected to be long enough to dry them out, yet without a strong rational for selection of drying times that range from a few hours to a few days (Bowen et al. 2013; Burakov and Nachasova 2013; Numrich et al. 594 2015). These studies used samples that are of typical size $0.5-10 \mathrm{~g}$, greater than the size of the individual granules 595 used in the present work (maximum size of approx. 0.3g). For experiments where a fixed duration was used, without 596 drying to constant mass being recorded, there is no certainty the samples actually did dry out. For the experiments 597 where samples were stated as drying to constant mass (Wilson et al. 2009; 2012), no evidence or data to support this 598 is presented.

599 There is support for the findings of the present work in the publications of Bowen et al. (2011), Le Goff and Gallet 600 (2014; 2015a), Gallet and Le Goff (2015) and Zhao et al. (2015). Bowen et al. (2011, Figure 3) produced drying 601 curves that demonstrated that after a period of 2 weeks drying at $100^{\circ} \mathrm{C}$ constant mass had still not been achieved; 602 however, they do not pursue the matter much further and this was for relatively large samples, 32-96g. Le Goff and 
Gallet $(2014 ; 2015 \mathrm{a})$ draw attention to the need for better understanding of the effects of drying temperature and duration, finding that for longer drying times or higher temperatures there is an additional/greater mass loss

605 (observable in a shift in the subsequent mass gain curves to lower mass, see Figure B of Le Goff and Gallet (2014)). Unfortunately, they do not record the mass of the samples as a function of drying time, so again it is not possible to know if, even for the longest drying times used, 14 days, complete drying occurred. From Gallet and Le Goff (2015) there is strong evidence that incomplete drying occurs for the duration used (5hrs) while heating at lower temperatures $\left(60,85,105,130^{\circ} \mathrm{C}\right)$ with increases to the next highest temperature producing greater mass loss and mass gain rates. of a drying temperature of $300^{\circ} \mathrm{C}$. achieved, with evidence that it is instead prolonged (Bowen et al. 2011, Zhao et al. 2015) and poorly understood (Le Goff and Gallet (2014; 2015a); Gallet and Le Goff 2015). The present work suggests that drying is a non-trivial issue such that even after two months drying at temperatures of $130^{\circ} \mathrm{C}$ and granules of $<0.2 \mathrm{~g}$ there is still considerable potential for water to be removed.

617 As well as this, there is the question over the nature of the water being removed; is it solely physisorbed/pore/capillary water that is loosely held/bound (Wilson et al. 2009; 2012) or is chemisorbed water also being removed (e.g. Gallet and Le Goff 2015; Barrett 2015; 2017b), with the latter responsible for the prolonged behaviour, particularly in low

620 surface area well-behaved samples (see Barrett 2015; 2017b). If the remaining moisture not removed after 60 days 621 drying is attributed to loose water, $m_{l w}$, then it needs to be subtracted from the total mass loss, $m_{R H X C}$, upon reheating at $500^{\circ} \mathrm{C}$ in order to obtain the RHX related mass loss, $m_{R H X}$ (Barrett 2015; 2017a). However, this assumption of 623 drying only removing physisorbed water was originally guided by assertions that equilibration of the mass occurred 624 following drying (Wilson et al. 2009; 2012). The work of Le Goff and Gallet (2014; 2015a), Gallet and Le Goff 625 (2015) and Barrett (2015) demonstrate that this is not the case, and, further, that those assertions were not well 626 supported experimentally (Le Goff and Gallet 2015a). Instead, it seems increasingly likely (Gallet and Le Goff 2015; 627 Barrett 2015; 2017b), that the two stage mass gain behavior, with Stage 2 described well by a $t^{l / n}$ model, following 628 drying is a chemisorption driven process and associated with the removal of chemisorbed water during drying. Interestingly, this seems supported by the result that the only sample to fully dry was Esp for which Event B (TG-MS 
data, Table 3, associated with a chemisorption process by Barrett 2015; 2017b) was low in magnitude and with a peak water removal temperature of $110^{\circ} \mathrm{C}$, the lowest for samples where Event $B$ was certain, and well below the drying

632 temperature of $130^{\circ} \mathrm{C}$ used in mass gain tests.

633 If prolonged drying is associated with chemisorption (with removal of loose water completed at some earlier point)

634 then it may not be necessary to estimate or subtract the quantity $m_{l w}$ if the component based approach proposed by Barrett $(2015 ; 2017)$ is valid. This approach will not be discussed but provided all physisorbed water is removed then

636 the remaining chemisorbed water not removed is taken account of in its methodology. The implications of this are 637 dealt with in Barrett (2015).

638
In any case, the present work demonstrates that complete drying is unlikely or impractical using simple oven based setups and highlights the need for more controlled recording of the mass loss curves during drying in order to (a) assess the quantity of loose water remaining (if drying is associated with loose water removal alone) or (b) to provide evidence that the stage associated with removal of loose water is complete, with continued mass loss due to removal of chemisorbed water. Modelling of the mass gain curves using the approaches above could be used in (a) and may be useful in observing transitions in (b).

\subsection{Carbon Content}

It can be observed from that carbon (organic) context was significant in all samples regardless of the context of retrieval, varying from $0.0035-0.5198 \%$ wt, Figure 6 . As well as this, there does not appear to be notably lower levels present in non-buried samples; this is made clear by the high carbon content in $\mathrm{Cau}, \mathrm{Por}$ and $\mathrm{Bel}$, and highlight that significant quantities of organic matter should be treated as plausible mass contaminants in all samples used in future RHX dating trials. It is also worth noting that the highest levels were obtained for the samples Por, Etr, Bel, Dow1, Dow2, Rom, Cau (0.52-0.05\%wt) and this will be returned to later. From the TG-MS data, Table 3 and Figures 7-8, it is clear that at heating temperatures from $200-300^{\circ} \mathrm{C}$ mass loss associated with $\mathrm{CO}_{2}$ removal commences, Event E, corresponding to commencement of the removal of organics (Ford 1967; Rice 1987; Dunham 1992; see Barrett 2015 for a more detailed review of mass loss temperatures associated with firing of ceramics). This removal appears to peak or plateau in the range $400-500^{\circ} \mathrm{C}$, Event $F$, however is not complete until higher temperatures. This is supported by the FTIR data, Figures 15-16 and Table 6, where the presence of organics peaks in region $2800-3000 \mathrm{~cm}^{-}$ ${ }^{1}$ is still strongly detected even after reheating of powdered samples $(<63 \mu \mathrm{m})$ at $500^{\circ} \mathrm{C}$ for 18 hours. This is an area 
of concern for RHX dating where it is essential that the carbon removed during heating at $500^{\circ} \mathrm{C}$ equates to that measured as part of carbon content analysis.

From the FTIR identification in the region $3000-2800 \mathrm{~cm}^{-1}$, four main bands are identified as present in both the nonreheated and reheated samples, Table 6 and Figure 13-15. This region of $\mathrm{CH}$ absorption was selected because it is absent of mineral interference and subjectivity issues associated with other regions (see Reeves III 2012). A possible band at $2860-2870 \mathrm{~cm}^{-1}$, present only in the non-reheated samples, appears to be only an effect of the broad absorption band ranges assigned to samples in Figure 14 because of uncertainty in the peak and is not considered real. The remaining four peaks, summarised below in Table 8, together with infrared bond assignments and organic source interpretations, are made up of the dominant bands, $2845-2860 \mathrm{~cm}^{-1}, 2920-2930 \mathrm{~cm}^{-1}$, and $2950-2975 \mathrm{~cm}^{-1}$ and a lesser band at $2870-2890 \mathrm{~cm}^{-1}$. These bands are identified as due to bonds associated with organic matter (CH bonds), specifically aliphatic stretching and bending bonds, Table 8 (identified using Larkin 2011). According to Larkin (2011) the aliphatic stretching bonds often appear as a pair of doublets (in phase, out of phase) and it appears that two sets of doublets are observed in the present work, Table 6, one associated with $\mathrm{R}^{-\mathrm{CH}_{3}}$ stretching and the other associated with $\mathrm{R}-\mathrm{CH}_{2}-\mathrm{R}$ ( $\mathrm{R}$ is an unspecified group/molecule attached).

Table 8: Table of main FTIR peaks associated with organic matter, together with IR bond assignments, possible organic matter source, and associated references.

\begin{tabular}{|c|c|c|c|}
\hline $\begin{array}{l}\text { Wavenumber } \mathrm{cm}^{-1}(\mathrm{n}=\text { non- } \\
\text { reheated,r=reheated })\end{array}$ & $\begin{array}{l}\text { IR bond } \\
\text { Assignment } \\
\text { (Larkin 2011) }\end{array}$ & $\begin{array}{l}\text { Suspected/Potential } \\
\text { Source Organic }\end{array}$ & Reference \\
\hline $\begin{array}{l}1 . \\
\text { Peak }=2854(\mathrm{n}, \mathrm{r}) \\
\text { Range=2845-2860 }\end{array}$ & $\begin{array}{l}\text { Aliphatic } \\
\text { R-CH }-\mathrm{R} \\
\text { Stretching (in } \\
\text { phase) }\end{array}$ & $\begin{array}{l}\text { Humic/Fulvic Acids } \\
\text { Peat-Anthracite (coke) }\end{array}$ & $\begin{array}{l}\text { Vergnoux et al. } 2011 \\
\text { Reeves III } 2012 \\
\text { Madari et al. } 2006\end{array}$ \\
\hline $\begin{array}{l}2 . \\
2880(\mathrm{n}, \mathrm{r}) \\
2870-2890\end{array}$ & $\begin{array}{l}\text { Aliphatic } \\
\text { R-CH } \\
\text { Stretching (in } \\
\text { phase) }\end{array}$ & Not Clear & -- \\
\hline $\begin{array}{l}3 . \\
2925(\mathrm{n}, \mathrm{r}) \\
2920-2930\end{array}$ & $\begin{array}{l}\text { Aliphatic } \\
\text { R-CH }-\mathrm{CH}_{2}-\mathrm{R} \\
\text { Stretching (out } \\
\text { of phase) }\end{array}$ & $\begin{array}{l}\text { Humic/Fulvic Acids } \\
\text { Peat-Anthracite (coke) }\end{array}$ & $\begin{array}{l}\text { Vergnoux et al. 2011, } \\
\text { van der Marel et al. } 1976 \\
\text { Reeves III } 2012 \\
\text { Madari et al. } 2006 \\
\end{array}$ \\
\hline $\begin{array}{l}4 . \\
2960,2970(n, r) \\
2950-2975\end{array}$ & $\begin{array}{l}\text { Aliphatic } \\
\text { R-CH } \\
\text { Stretching (out } \\
\text { of phase) }\end{array}$ & $\begin{array}{l}\text { Hard Coal, Brown Coal, } \\
\text { Coke }\end{array}$ & $\begin{array}{l}\text { van der Marel et al. } 1976 \\
\text { Guisnet and Magnoux } 2001\end{array}$ \\
\hline
\end{tabular}


675 Possible organic sources are included in Table 8 together with references for the identification at these bands; however, 676 no source could be assigned to the band at $2870-2890 \mathrm{~cm}^{-1}$ and the sources for the remaining bands are by no means 677 certain. The organic matter in soils is often characterised by a double absorption band at $2855 \mathrm{~cm}^{-1}$ and $2930 \mathrm{~cm}^{-1}(\mathrm{e} . \mathrm{g}$. 678 Madari et al. 2006; Vergnoux et al. 2011; Reeves III 2012), yet with no peak at 2950-2975 $\mathrm{cm}^{-1}$ identified by these 679 authors. Fernandes et al. (2010) provide FTIR spectra of the organic matter, humic and fulvic, in some soils and peats; 680 again the double peak at $2855 \mathrm{~cm}^{-1}$ and $2930 \mathrm{~cm}^{-1}$ is evident yet any peak at 2950-2975 $\mathrm{cm}^{-1}$ is absent. Chen et al. 681 (2012) carried out FTIR on a suite of coals varying from peat to anthracite and again the double peaks at $2857 \mathrm{~cm}^{-1}$ and $2927 \mathrm{~cm}^{-1}$ were observed without any third peak apparent (this is supported by similar work by Tian et al. 2010 ).

683 In this regard, the strong triplet of peaks observed in this study may be more characteristic of a triplet of peaks 684 identified by van der Marel and Beuterspacher (1976) at $2950 \mathrm{~cm}^{-1}, 2920 \mathrm{~cm}^{-1}$, and $2850 \mathrm{~cm}^{-1}$, found in peat, black peat, brown coal, lignite, hard coal and bitumen. The presence of substances derived from the peat-to-anthracite formation group is certainly possible for raw clays (Dunham 1992), yet it seems unlikely, given the high firing temperatures interpreted for most of the samples (Barrett 2015), that much, if any, of these substances would survive. It is conceivable that, in a reduced (oxygen deprived) firing environment within the kiln (or even within the brick), carbonrich coke may have been produced and that the major absorption triplet observed in the data could be explained by similar triplet of peaks at $2860 \mathrm{~cm}^{-1}, 2930 \mathrm{~cm}^{-1}$, and $2970 \mathrm{~cm}^{-1}$, as observed in Guisnet and Magnoux (2001). The use of coke as a fuel in the firing of bricks (in clamps and kilns) is/was not uncommon (Hammond 1981; Brunswick 1990; Pavía and Bolton 2000) and this could also be a source of contamination, particularly post-firing.

From the above, it can not be clarified whether the source of the organics is humic-related substances or derived from 694 part of the peat-to-anthracite formation pathway. From TG-MS, the organics are predominantly being burnt off at temperatures well below the original firing temperature, i.e. less than $500^{\circ} \mathrm{C}$ and certainly not above $800^{\circ} \mathrm{C}$, suggesting that the source of organics removed during the RHX methodology are more likely to be post-firing contamination 697 from burial or air-borne/rain precipitated processes, presumably humic-related substances. That the source of organic matter is likely to be post-firing contamination may be supported by findings from BET analysis, presented in Barrett (2015), where the samples with highest surface area (Table S.3) and pore volume (with the exception of Lan where the carbon content is very low) are also those with the highest carbon contents above (and calcite content, dealt with 701 in Barrett 2015). In Barrett (2015) the BET surface area is also highly correlated $\left(R^{2}=0.90\right)$ with the percentage of water removed in the TG-MS heating regime $50-130^{\circ} \mathrm{C}$ (Figure 5.34 of Barrett 2015), with the greatest quantities of 
water loss also occurring for the samples with highest surface area and pore volume, (Figure 5.29 of Barrett 2015). This suggests that high pore volume and surface area may be associated with, and permit, greater uptake of environmental moisture (groundwater, rain), and with it sources of carbon and calcite contamination, supporting an argument that much of the carbon content is derived from post-firing organics of humic origin.

It is not ideal that for each sample only a single estimate of the carbon content was carried out using two measurements of the carbon content of two subsamples, one of which had been previously heated to $500^{\circ} \mathrm{C} .{ }^{1}$ These subsamples were taken from a well-mixed powder of the remaining granules from which the dating subsamples were taken. Hence, the samples used in carbon content analysis are expected to be well homogenised and representative of the dating samples in their carbon content. ${ }^{2}$ Nonetheless, variation is to be expected, and with only a single estimate carried out per sample the repeatability of carbon content measurements and the associated uncertainty can not be estimated. As well as this there will be sources of uncertainty in the procedure used for its estimation. However, the author worked under the assumption that the uncertainties in the carbon content, associated with subsample variation and the experimental method, would be minor when compared with that associated with the organic matter to organic carbon ratio; the range of the $\mathrm{OM} / \mathrm{OC}$ uncertainty used was $1.4-2.5$, which equates to a percentage uncertainty of $28 \%$ in the mass of organic matter (based on $\mathrm{OM} / \mathrm{OC}$ ratio of 1.95 used in age estimates), and was considered broad enough to encompass and take account of any sources of uncertainty in the carbon content. These values for the organic matter to organic carbon ratios are based on a survey of research focussed on its estimation for organic matter from a range of environments (aerosol-borne, soil, peats, clays), presented in Table 9. This survey, while not comprehensive, demonstrates that the $\mathrm{OM} / \mathrm{OC}$ ratio can vary considerably but for all studies falls within the range 1.0-3.0. Notable

722 attention is given to the work of Pribyl (2010) who in a review of 26 existing publications concluded that " $a$ consideration of the possible variation in organic matter composition predicts a range of factor values between 1.4 and 2.5". This range is used in the present work as an adequate, if not ideal, reflection of the range of likely ratios for contaminants found in ceramics, aerosol-borne or burial-related.

\footnotetext{
${ }^{1}$ This was constrained by the large number of samples, 36, which needed to be prepared and analysed. Ideally, the carbon content of the subsamples used in mass gain experiments would be captured during heating at $500^{\circ} \mathrm{C}$; if conducted on the three subsamples, this would also provide some useful information on the homogeneity of the samples and uncertainty in the carbon content.

${ }^{2}$ The XRD, FTIR, and XRF analysis has demonstrated that the two subsamples used in reheated and non-reheated tests were almost identical both mineralogically and in elemental composition.
} 
727 Table 9: A short survey of the organic matter to organic carbon ratios from publications focussed on different 728 environments/sources of organic matter.

\begin{tabular}{|c|c|c|}
\hline Environment/Source & OM/OC typical value & OM/OC range \\
\hline \multicolumn{3}{|l|}{ Aerosol } \\
\hline Ruthenberg et al. 2014 & 1.69 & 1.4-2.15 \\
\hline El-Zanan et al. 2009 & 1.92 & $1.52-2.32$ \\
\hline \multirow[t]{2}{*}{ Phillips et al. 2014} & 1.5 (urban) & not clear \\
\hline & 2.0 (rural) & not clear \\
\hline \multirow[t]{2}{*}{ Turpin and Lim 2001} & 1.6 (urban) & \begin{tabular}{|l|}
$1.4-1.8$ \\
\end{tabular} \\
\hline & 2.1 (non-urban) & $1.9-2.3$ \\
\hline \multicolumn{3}{|l|}{ Soil } \\
\hline Pribyl 2010 (Review) & Soil & \\
\hline Soil & 2.0 & $1.4-2.5$ \\
\hline Humin & - & $1.49-1.61$ \\
\hline Humic Acid & - & $1.70-1.85$ \\
\hline Fulvic Acid & - & $1.96-2.44$ \\
\hline Carbohydrate & - & $2.22-2.5$ \\
\hline Lipids & - & $1.27-1.45$ \\
\hline Amino Acids & - & $1.54-3.0$ \\
\hline \multicolumn{3}{|l|}{ Peats } \\
\hline \multicolumn{3}{|l|}{ Klingenfuß et al. 2014} \\
\hline Own Work & $\begin{array}{l}\text { 1.73-2.41 (dependent on } \\
\text { peat type) }\end{array}$ & $1.64-2.97$ \\
\hline Review of existing work & - & $1.55-2.31$ \\
\hline \multicolumn{3}{|l|}{ Clays } \\
\hline \multicolumn{3}{|l|}{ Worrall 1956} \\
\hline Ball Clays & 1.56 & $1.51-1.61$ \\
\hline Fireclays & 1.26 & $1.15-1.37$ \\
\hline
\end{tabular}

The mass of organic matter, $m_{O M}$, is a considerable fraction (5-20\% typically for better behaved samples on which dating attempts could be made, see Barrett 2015; 2017a) of the total mass loss, $m_{R H X C}$, during reheating, Figure 7, and

732 is subtracted (along with loose water, for example) from this quantity in order to obtain the RHX mass used in age 733 estimations, $m_{R H X}$. Therefore, the range of uncertainty used for the OM/OC ratio has a considerable effect on the 734 estimated ages of the samples, Table 4 and Figure 8, causing an uncertainty in the age range of a minimum of 35yrs 735 (for $\mathrm{Cal}$ and $t^{l / n}$ ) but more typically on the order of at least 100 years for samples where the age estimates are in closest 736 agreement with the known ages (Barrett 2015; 2017a). For example, with the best sample using the $t^{1 / 4}$ model the 737 uncertainty associated with the OM/OC ratio leads to an age range for Joy of 321-489 years. If the mid-point in the 
range is used ${ }^{3}$ this can be re-written as $405 \pm 84$ years, or a percentage uncertainty of $20 \%$. For the best samples using

$739 t^{1 / n}$, the age range in Ann is 59-182 years, or $120 \pm 60$ years, a percentage uncertainty of $50 \%$. The effects are quite

740 considerable, then, but do not explain the issue of large ages in most samples.

741 It is clear then that the presence of organic matter is a serious issue for RHX dating, as previously stated by Numrich 742 et al. (2015), not alone because of the magnitude in which it can occur, but also because it has been found to be present 743 in significant quantities in all samples (only Lan had very low levels), whether the samples were buried during their 744 lifetimes or just exposed to atmospheric conditions. This ubiquitous presence of organic matter raises further questions 745 (in addition to those previously raised by Le Goff and Gallet 2015a; see also the review in Barrett 2015) surrounding good RHX dates obtained in previous studies, where the presence of organic matter was either not examined or treated

747 in a very limited fashion (Wilson et al. 2009; 2012; discussed further in Barrett 2015). It also may be a contributor to 748 poor dates obtained in other studies where the organic matter was not quantified (for example Burakov and Nachasova 2013; Le Goff and Gallet 2014; 2015a). Therefore, in all future RHX dating trials the presence of organic matter needs to be examined out and, if suitable quantification is not possible, a method of its removal is required. Wet chemistry methods may be an option. Numrich et al. (2015) consider the removal of contamination as mandatory and tested several wet chemistry pre-treatments (acid-base leaching, wet oxidation) for the removal of organic carbon. All approaches reduced the carbon content (oxidation, $\mathrm{H}_{2} \mathrm{O}_{2}$, proving most successful) but none were successful in 754 providing a complete removal; for this reason the authors recommended pre-treatment cleaning of RHX samples before mass gain tests, with samples still displaying large carbon content following treatment to be discarded. They also stress that these treatments could potentially remove some hydroxyls, or lead to additional hydroxylation. Further 757 work examining the composition (e.g. mineralogy, surface area) and mass loss change in contaminant-free samples 758 with different pre-treatments would be very useful; note that consideration must also be given to the potential effects 759 heating conducted during pre-treatment (Numrich et al. used $60^{\circ} \mathrm{C}$ for durations of $60-755$ minutes) might have on 760 accelerating the rehydroxylation in the ceramics (see the discussion on short term elevated temperature event 761 (STETES) in Barrett 2015).

\footnotetext{
${ }^{3}$ The age estimate based on an OM/OC of 1.95 was $399 \mathrm{yrs}$ old. However, the effects of uncertainties on the age are not symmetric, because the age is proportional to mass ${ }^{4}$.
} 


\subsection{Mineral Alteration}

764 The differences between the reheated and non-reheated XRD and FTIR spectra showed no appreciable differences 765 (see for example Figure 9) associated with mineral alteration during reheating at $500^{\circ} \mathrm{C}$, samples $\mathrm{Mac}$ and $\mathrm{Bel}$ aside. 766 In associated work (Barrett 2015), it is demonstrated (using XRD, FTIR, petrography) that all samples, with the 767 exception of Etr and Rom, were likely fired at temperature exceeding $850^{\circ} \mathrm{C}$, indicated by the presence of hightemperature mineral phases such as cristobalite, spinel and gehlenite. For Etr and Rom there is some evidence (calcite breakdown) suggesting original firing temperatures exceeding $650^{\circ} \mathrm{C}$. Therefore, the results generally apply to well fired samples but are also the case for moderately fired samples. Given the reasonably large set of compositionally

771 diverse samples examined (see Barrett 2015; 2017a; 2017b for details on composition), mass loss associated with 772 mineralogical changes during the reheating stage of RHX is not found to be problematic, aside from gypsum related problems, supporting the findings in Gallet and Le Goff (2015, Figure 1). Also of note is that no mineralogical changes associated with goethite dehydroxylation were observed and, hence, no related mass loss issues (Burakov and

775 Nachosova 2013).

For Mac and Bel, mineralogical changes, Figures 10-11, are associated with the presence and dehydration of hydrated calcium sulfates (gypsum $\mathrm{CaSO} \cdot 2 \mathrm{H}_{2} \mathrm{O}$, bassanite $\mathrm{CaSO} \cdot 0.5 \mathrm{H}_{2} \mathrm{O}$ ) to anhydrite $(\mathrm{CaSO})$, that occur typically in the temperature range $120-160^{\circ} \mathrm{C}$ (Dunham 1992). For $\mathrm{Mac}$ and $\mathrm{Bel}$, the presence of gypsum was also detected in associated work, precipitated in the pores using petrography and also with sulphur detected using p-XRF ((Barrett 2015). The emission of $\mathrm{SO}_{2}$ at temperatures exceeding $650-700^{\circ} \mathrm{C}$, attributable to gypsum decomposition, is also observed in the TG-MS data, Table 3 and Figure 11.

The presence of gypsum and its dehydration during heating at $500^{\circ} \mathrm{C}$ for samples $\mathrm{Mac}$ and $\mathrm{Bel}$ is also associated with a large difference between the $S 1$ mass gains, $m_{S 1}$, of the $130 \mathrm{C}$ and $500 \mathrm{C}$ components $\left(25^{\circ} \mathrm{C}\right.$ aging $)$, for example Figure 12 and Table 5, a difference not found to be significant in the other samples (Barrett 2015). There are then two possible issues associated with gypsum. Firstly, there is a mass of water loss during dehydration of gypsum when the samples are heated between $130-500^{\circ} \mathrm{C}$; this mass loss will be included falsely in the total fractional mass estimate, $m_{R H X C}$, resulting in an erroneous increase in the age estimate. Secondly, if the level of physisorption is reduced following the conversion of gypsum/bassanite to anhydrite, then the magnitude of this difference will also be reflected 

physisorption is the same for both the $130^{\circ} \mathrm{C}$ and $500^{\circ} \mathrm{C}$ components).

791 In the present work, there is no estimate available for the mass loss due to dehydration of gypsum but an estimate for 792 the change in physisorption level is available. This is worth commenting on in terms of the magnitude of the effect it 793 might have on the age estimates in Barrett (2015;2017a), particularly considering that Mac has the highest mass 794 discrepancy (0.00513 and 0.00504, fractional mass for $t^{1 / 4}$ and $t^{1 / n}$ models, respectively; the mass discrepancy 795 corresponds to the quantity of excess mass the RHX mass, $m_{R H X}$, used in age estimates needs to be reduced by to find 796 agreement with the known age) of all samples for both models and $\mathrm{Bel}$ is the second highest for the $t^{1 / n}$ model $(0.00079$ 797 and 0.00152 for $t^{1 / 4}$ and $t^{l / n}$ models, respectively). The experimental estimates of $m_{S l}$ are only approximate (Barrett 798 2015), but the differences between the $130^{\circ} \mathrm{C}$ (the larger gain) and the $500^{\circ} \mathrm{C}$ components, $m_{S I-130}-m_{S 1-500}$, are as 799 follows: for Mac, $0.00236\left(t^{1 / 4}\right)$ and $0.00235\left(t^{1 / n}\right)$; for Bel, $0.00355\left(t^{1 / 4}\right)$ and $0.00385\left(t^{1 / n}\right)$. The magnitude is clearly 800 of a similar order to that observed for the mass discrepancies of these samples, particularly for the $t^{l / n}$ model, and 801 therefore, gypsum dehydration, even only considering its effects on physisorption, may be a very significant 802 contributor to issues encountered with the estimated ages of these particular samples. More focussed work on the 803 hydration properties of anhydrite and gypsum in fired clays following heating is required. Screening of samples for 804 gypsum, particularly brick as gypsum can be produced by the reaction of sulphuric acid and calcite (in the composition 805 of the brick or through leaching of surrounding mortars) during weathering (Prentice 1990; Pavía and Bolton 2000), 806 is recommended together with increased examination of methods for its removal that do not interfere with the RHX 807 methodology. 


\section{Conclusion}

815 Research conducted within the framework of a larger study examining the mass gain behaviour of archaeological ceramics (predominantly bricks) and the application of an RHX dating methodology (component based approach) has

817 revealed new, or provided a better understanding of, mass loss issues that occur during drying or reheating.

818 In particular, drying of ceramics by conventional (oven) methods requires a prolonged and indefinite period (minimum 819 of months), well beyond that carried out in existing work. Modelling of loose water not removed is a possible solution, 820 however this requires high precision recording of the mass loss curves during drying. Alternatively, if the prolonged

821 drying is due to removal of chemisorbed water, as argued for by the present author, then incomplete drying is not 822 problematic and issues of remaining loose water could potentially be resolved using a component based approach.

823 The organic matter present in samples is a serious concern for RHX dating and its validation. All samples, regardless 824 of their retrieval context, had significant quantities of carbon present, corresponding to $10-50 \%$ of the total mass loss 825 during reheating. This has been attributed to organic matter, most likely humic related substances or coke. On account 826 of large uncertainties in the organic matter to organic carbon ratios (OM/OC), the estimation of the mass of organic 827 matter removed during reheating is problematic; on account of this, the age range estimates of samples are badly 828 affected, often varying from $20-50 \%$ of the age of well-behaved samples in associated dating trials. In future dating 829 trials, screening and alternative methods for estimating the organic matter mass are required.

830 Mineralogical changes during reheating were generally negligible and not considered problematic with the exception 831 of samples where gypsum is present. Dehydration of gypsum during heating leads to an unwanted component of mass

832 loss that is difficult to quantify. As well as this physisorption levels (Stage 1) are altered, requiring some alterations 833 of the equations used in age estimations. Screening of samples is recommended in future work.

834 The above mass loss issues all have the potential to adversely affect any future RHX dating trials and will require focussed treatment in future work. 
This work was conducted as Ph.D. research (accessible) made possible through the aid of a Department for

841 Employment and Learning (DEL) Ph.D. studentship for which I am grateful. Acknowledgements are also made of the

842 assistance provided by the School of Geography, Archaeology and Palaeoecology where this research was conducted.

843 I wish to thank the following persons both for aiding source and for providing samples: Prof. Caroline Malone (QUB),

844 Mr. Michael Barrett (Turlough), Dr. Joanne Curran (Consarc Design Group), Mr. Peter Francis (Ballynahinch), Ms.

845 Audrey Gahan (Gahan and Long Arch. Serv. Ltd), Mr. Stephen Gilmore (Northern Arch. Cons. Ltd), Mr. Barrie

846 Hartwell (GAP, QUB), Mr. Paul Logue (N. Ireland Environment Agency), Dr. Sara Pavía (Trinity College Dublin),

847 Mr. Cormac McSparron and Mr. Ruairí Ó Baoill (Centre for Archaeological Fieldwork, QUB). For technical

848 assistance and advice, I thank the following persons: Mr. Pat McBride (QUB), Mr. John Meneely (QUB), Mr. Peter

849 Gray, Mr. Stephen Roper, and Mr. Jim McDonald $\left({ }^{14}\right.$ CHRONO Centre, QUB), Dr. Jennifer McKinley (GAP, QUB),

850 Dr. John Caulfield (SPACE, QUB), Dr. Rory Flood (GAP, QUB), Mr. Mark Russell (SPACE, QUB) Mr. William

851 Harra (ASEP, QUB).

852 I also wish to thank Prof. Paula Reimer for her helpful comments with regard to preparation of this text.

853

854

855

856

857

858

859

860

861 


\section{References}

864 Barrett, G. T. 2015. Rehydroxylation Dating: Assessment for Archaeological Application. School of Geography, 865 Archaeology and Palaeoecology, Queen's University Belfast. Unpublished Ph.D. thesis.

866 http://pure.qub.ac.uk/portal/en/publications/rehydroxylation-dating-assessment-for-archaeological-

867 application(9c89d2bd-ceaf-4f3d-a9d0-515eb23e6204).html (accessed 19/01/17)

Barrett, G. T. 2017a. Rehydroxylation (RHX) dating: Trials on post-medieval brick using a component based 869 approach. Journal of Archaeological Science: Reports. (accepted)

870 Barrett, G. T. 2017b. Processes and kinetics of mass gain in archaeological brick following drying and reheating. 871 Journal of American Ceramic Society. (accepted)

872 Benedetto, G. E. de, Laviano, R., Sabbatini, L. and Zambonin, P. G. 2002. Infrared spectroscopy in the 873 mineralogical characterization of ancient pottery. Journal of Cultural Heritage. 3 177-186

874 Bowen, P. K., Ranck, H. J., Scarlett, T. J. and Drelich, J. W. 2011. Rehydration / rehydroxylation kinetics of 875 reheated XIX-century Davenport (Utah) Ceramic. Journal of the American Ceramic Society. 94 2585-2591

876 Bowen, P. K., Drelich, J. and Scarlett, T. J. 2013. Modeling rehydration/rehydroxylation mass-gain curves from 877 Davenport ceramics. Journal of the American Ceramic Society. 96 885-891

878 Brosnan, D. A. and Robinson, G. C. 2003. Introduction to Drying of Ceramics. The American Ceramic Society. p. $879 \quad 69$

880 Brunswick, R. W. 1990. Brick Building in Britain. Victor Gollancz Ltd. London.

881 Burakov, K. S. and Nachasova, I. E. 2013. Archaeomagnetic study and rehydroxylation dating of fired-clay ceramics. 882 Izvestiya, Physics of the Solid Earth. 49 105-112

883 Chen, Y., Mastalerz, M. and Schimmelmann, A. 2012. Characterization of chemical functional groups in macerals 884 across different coal ranks via micro-FTIR spectroscopy. International Journal of Coal Geology. 104 22-33 
Dunham, A. C. 1992. Developments in industrial mineralogy: I. The mineralogy of brick-making. Proceedings of the Yorkshire Geological Society. 49 95-104

El-Zanan, H. S., Zielinska, B., Mazzoleni, L. R. and Hansen, D. A. 2009. Analytical determination of the aerosol organic mass-to-organic carbon ratio. Journal of Air Waste Management Association. 59 58-69 of peat and soil samples and their respective humic substances. Journal of Molecular Structure. 971 33-38 gain analyses versus annealing temperatures. Journal of the American Ceramic Society. 98 2738-2744 96

Hammond, M. 1981. Bricks and Brickmaking. Shire Publications Ltd. Oxford.

Highscore. 2015. PANalytical X-ray diffraction software website. [Online] http://www.panalytical.com/Xraydiffraction-software/HighScore-with-Plus-option.htm. [accessed 10th June 2015].

900 ICDD. 2015. International Centre for Diffraction Data PDF-2 Database Website. [Online] 901 http://www.icdd.com/products/pdf2.htm. [accessed 10th June 2016].

902 Klingenfuß, C., Roßkopf, N., Walter, J., Heller, C. and Zeitz, J. 2014. Soil organic matter to soil organic carbon ratios 903 of peatland soil substrates. Geoderma. 235-236 410-417

904 Larkin, P. 2011. Infrared and Raman Spectroscopy; Principles and Spectral Interpretation. Elsevier. MA. device. Quaternary Geochronology. 20 89-98 

ceramics. Journal of the American Ceramic Society. 98 398-401

912 Madari, B. E., Reeves III, J. B. Machado, P. L. O. A., Guimarães, C. M., Torres, E. and McCarty, G. W. 2006. Mid913 and near-infrared spectroscopic assessment of soil compositional parameters and structural indices in two Ferrasols. Geoderma. $136245-259$

915 Marinos-Kouris, D. and Maroulis, Z. B. 2006. Basic process calculations and simulations in drying. In Mujumbar, A. 916 S. (Ed.) Handbook of Industrial Drying (3rd Edition). CRC Press. Florida. p. 81

917 Moore, D. M. and Reynolds, Jr., R. C. 1997. X-Ray Diffraction and the Identification and Analysis of Clay Minerals. 918 2nd Edition. Oxford University Press. Oxford.

919 Numrich, M., Kutschera, W., Steier, P., Sterba, J.H. and Golser, R. 2015. On the effect of organic carbon on rehydroxylation (RHX) dating. Journal of Archaeological Science. doi: 10.1016/j.jas.2015.01.016.

921 Padowski, Z. and Mujumbar, A. S. 2006. Basic process calculations and simulations in drying. In Mujumbar, A. S. 922 (Ed.) Handbook of Industrial Drying (3rd Edition). CRC Press. Florida. p. 53

923 Pavía, S. and Bolton, J. 2000. Stone, Brick and Mortar: Historical Use, Decay and Conservation of Building Materials 924 in Ireland. Wordwell. Bray.

925 Philip, S., Martin, R. V., Pierce, J. R., Jimenez, J. L., Zhang, Q., Canagaratna, M. R., Spracklen, D. V., Nowlan, C.

926 R., Lamsal, L. N., Cooper, M. J., and Krotkov, N. A. 2014. Spatially and seasonally resolved estimate of the ratio of 927 organic matter to organic carbon. Atmospheric Environment. 87 34-40 

$508-513$

Rice, P. M. 1987. Pottery Analysis: a Sourcebook. University of Chicago Press. Chicago.

932 Russell, J. D. and Fraser, A. R. 1994. Infrared methods. In Wilson, M. J. (ed.) 1994. Clay Mineralogy: Spectroscopic and Chemical Determinative Methods. Chapman and Hall. London. p. 11-67 and organic matter to organic carbon ratios by infrared spectroscopy with application to selected sites in the improved network. Atmospheric Environment. 86 47-57

937 Tian, D., Liu, X. and Ding, M. 2010. CS $_{2}$ extraction and FTIR \& GC/MS analysis of a Chinese brown coal. Mining Science and Technology. 20 0562-2565

Turpin, B. J. and Lim, H. J. 2001. Species contributions to PM2.5 mass concentrations: revisiting common assumptions for estimating organic mass. Aerosol Science and Technology. 35 602-610

941 Van der Marel, H. W. and Beutelspacher, H. 1976. Atlas of Infrared Spectroscopy of Clay Minerals and their 942 Admixtures. Elsevier. Amsterdam.

943 Vergnoux, A., Guilano, M., Di Rocco, R., Domiezel, M., Théraulaz, F. and Doumenq, P. 2011. Quanitative and mid944 infrared changes of humic substances from burned soils. Environmental Research. 111 205-214

945 Wilson, M. A., Carter, M. A., Hall, C., Hoff, W. D., Ince, C., Savage, S. D., McKay, B. and Betts, I. M. 2009. Dating 946 fired-clay ceramics using long-term power law rehydroxylation kinetics. Proceedings of the Royal Society A. 465 $947 \quad 2407-2415$

948 Wilson, M. A., Hamilton, A., Ince, C., Carter, M. A. and Hall, C. 2012. Rehydroxylation (RHX) dating of 949 archaeological pottery. Proceedings of the Royal Society A. 468 3476-3493 
951 Zhao, S., Bowen, P. K., Drelich, J. W. and Scarlett, T. J. 2015. Reproducibility in rehydroxylation of ceramic artifacts.

952 Journal of the American Ceramic Society. 98 3367-3372

953

954

955

956

957

958

959

960

961

962

963

964

965

966 